\title{
ESTUDIO APLICADO SOBRE LA DESFORMALIZACIÓN DEL PROCEDIMIENTO JUDICIAL DE FAMILIA*
}

\author{
Francesco Carretta Muñoz ${ }^{* *}$
}

RESUMEN: Se examina la noción de desformalización del procedimiento que es uno de los mecanismos adjetivos introducidos por la ley 19.968 para lograr la adecuada tutela de los derechos de familia. Este segundo enfoque, de otro teórico ya concluido, contempla un estudio empírico sobre el instituto. Se trata de un examen cualitativo, no estadístico, sobre la tendencia de interpretación y aplicación que un grupo de jueces de diversas regiones de Chile, tiene sobre el referido instituto. En aquel se aprecia que la mayoría de ellos le concede el carácter de un principio, en circunstancias que según el sentido que el legislador le dio, no lo es.

PALABRAS CLAVE: Procedimiento de familia - formas procesales análisis cualitativo - interpretación judicial - principios.

\section{EMPIRICAL STUDY ABOUT THE DEFORMALIZATION OF FAMILY COURT PROCEEDINGS}

ABSTRACT: The notion of procedural deformalization is studied here as one of the adjectives mechanisms introduced by Law 19.968, to ensure the adequate protection of the rights of families. This second approach from another theorist no longer alive, provides empirical analysis on it. It is not a statistic review but a qualitative one of the interpretation and

* Fecha de recepción: 31 de agosto de 2015.

Fecha de aceptación: 6 de mayo de 2016.

Este trabajo fue realizado en el marco y con el financiamiento del proyecto Fondecyt iniciación $\mathrm{N}^{\circ} 11130404$, titulado "Estudio sobre la desformalización del proceso judicial de familia e infancia, de cara a su adecuada interpretación y aplicación en la justicia de familia chilena”, del cual el autor de este trabajo es su investigador responsable. El autor agradece especialmente a los profesores Bruno Caponi, de la Università degli Studi di Firenze, y Jordi Nieva Fenoll, de la Universidad de Barcelona. También al ayudante de investigación de la PUCV David Navea.

** Profesor agregado de Derecho Procesal Civil de la Facultad de Derecho de la Pontificia Universidad Católica de Valparaíso. Profesor de Derecho Procesal Civil de la Universidad de Viña del Mar. Dirección postal: Facultad de Derecho, Pontificia Universidad Católica de Valparaíso, Casilla 4055, Valparaíso, Chile. Correo electrónico: francesco.carretta@ucv.cl. 
application trend of a group of judges from different regions of Chile has over the institute, and it seems that most of them give it the character of a principle, but by the sense that the legislature gave it, it is not.

KEY WORDS: Family related proceedings - procedural forms qualitative review - judicial interpretation - principles.

Sumario: Introducción. 1) Marco general. 2) Cuestión previa: alcances de la atribución del artículo 27 de la ley 19.968 versus los alcances de la desformalización. 3) Resultados del estudio aplicado. 3.1) Descripción del marco metodológico. 3.2) Precisiones iniciales y despeje de información. 3.3) La posibilidad de dictar sentencia en audiencia preparatoria. 3.4) Posibilidad de contestar la demanda en audiencia preparatoria. 3.5) La incidencia de la desformalización en el desarrollo secuencial de la audiencia preparatoria: confronte con la preclusión. 4) La desformalización no es un principio juridico. Conclusiones. Anexo.

\section{INTRODUCCIÓN}

La muestra inicial, teórica y general sobre el tópico en estudio ya fue dada a conocer en una publicación anterior ${ }^{1}$. En ella se plantearon hipótesis en torno a la desformalización. Principalmente, que no existe sobre la misma una interpretación uniforme y coherente por parte de la judicatura chilena, que en su mayoría le otorga la calidad de principio jurídico, en circunstancias que, de acuerdo a la ley, su contexto normativo, la teoría y las consecuencias prácticas de asumirla como tal, no lo es.

En esta segunda sección, se exhibirán los resultados de un examen aplicado, cuya metodología se sustentó en la recolección de opiniones planteadas por jueces de familia de diversas regiones del país, cuyo análisis social cualitativo está consignado en el anexo. La conexión entre este artículo y el anterior es general y cada uno conserva sus propios objetivos y parámetros, por lo que no necesariamente se debe recurrir al primero para entender este. No obstante, con el objetivo de delimitar y aportar mayor claridad a los resultados concretos que serán expuestos en adelante, se agregarán dos acápites. Un prolegómeno que contiene las

Carretta Muñoz, Francesco (2014) "La desformalización del proceso judicial de familia e infancia”. Revista de derecho Pontificia Universidad Católica de Valparaíso, Vol. XLII, $\mathrm{N}^{\circ} 1$, pp. 481-495. 
ideas matrices que inspiran toda la investigación y que fueron plasmadas en la primera entrega y al final, una sección donde se contrastarán los datos arrojados en la pesquisa, con uno de los postulados base que constituyen el sostén teórico de todo el estudio: el alcance de los principios jurídicos. Esta última parte será mayormente orientadora y enuncia brevemente algunos fundamentos. Aquel aspecto, junto a otros, pretenden ser desarrollados en profundidad en una tercera publicación ${ }^{2}$ que apunta a demostrar dogmáticamente el axioma planteado en el primer párrafo.

Durante el devenir de la investigación ${ }^{3}$ se constató un aspecto no previsto inicialmente: que las facultades que entrega al juez de familia en el artículo 27 de la ley 19.968 (en adelante LTF, ley de tribunales de familia), suelen confundirse por algunos jueces con aquellas que supuestamente entrega la desformalización. Por ello, se incorpora un capítulo (2) donde se analizará la cuestión, con el objeto de despejar las posibles confusiones que pueden surgir a raíz de aquella asimilación, y depurar con mayor rigor los contornos del instituto en referencia.

En concreto, el motivo de esta investigación es explorar la posibilidad que en la judicatura de familia chilena exista un mal entendimiento de la desformalización del procedimiento. Lo anterior con las consideraciones que el lector debe hacer frente a un estudio de carácter cualitativo como el que se presenta. En ningún caso se trata este de un estudio estadístico. Por tales prevenciones, mediante los datos empíricos presentados se intentará avizorar una tendencia y no una afirmación categórica a este respecto.

\section{1) MARCO GENERAL}

Todo el subsiguiente análisis tiene como punto de partida lo dispuesto en el artículo $9^{\circ}$ de la ley 19.968 que es necesario consignar: "Artículo $9^{\circ}$. - Principios del procedimiento. El procedimiento que aplicarán los juzgados de familia será oral, concentrado y desformalizado. En él primarán los principios de la inmediación, actuación de oficio y buisqueda de soluciones colaborativas entre partes."

Mediante la sola lectura de la norma, parece a primera vista que la desformalización, al encontrarse dentro del epígrafe referido a los

Artículo en actual proceso de revisión para publicación.

Véase anexo, apartado 1.3. 
principios del procedimiento de familia, pasa a ser uno de ellos en conjunto a la inmediación, actuación de oficio y la iniciativa conciliadora del juez. Sin embargo, una mirada aunque literal, medianamente aguda de la misma disposición, separa y distingue claramente, después del segundo punto seguido, las directrices del procedimiento con las características del mismo, quedando esta en el último apartado. Como correlato de aquello, la historia legislativa también dio cuenta que el legislador no tuvo en mente entregar a los jueces un principio jurídico a través de la figura en comento, por el temor que le generaba que pudiese crear por medio de él trámites o actuaciones no previstas en la ley. Ello, según quedó consignado en las actas de tramitación de la ley, implicaba que el juez podía inmiscuirse en atribuciones legislativas que no le son propias ${ }^{4}$. Tampoco en la Convención de Derechos del Niño suscrita por Chile el año 1990 hay indicio alguno sobre la desformalización como una de las vías de tutelar de mejor forma los derechos de los niños.

Pero dichos argumentos no se agotan allí, la historia fidedigna del establecimiento de la ley, que no estuvo exenta de pormenores ${ }^{5}$, otorga una mejor comprensión de lo que está significando. En sus anales se verifica que a su establecimiento, le antecedió la disposición siguiente:

"Artículo 10.- Desformalización. En silencio de la ley, el juez determinará la forma en que se verificarán las actuaciones y, en esta tarea, como en la de interpretar las normas del procedimiento, tendrá siempre presente que su objetivo es el adecuado resguardo de los derechos reconocidos por la ley y la más pronta y justa decisión de la controversia".

Este borrador luego se eliminó porque se estimó que la propuesta, no incidía en un tema de interpretación de la ley procesal, sino de creación normativa, lo que incursiona en atribuciones propias del legislador y no del juez de familia ${ }^{6}$. Se temió que este pudiese crear trámites o formas novedosas atentatorias de las facultades propias del ente legislativo y con esto se redujo su alcance a los límites que se aprecian en el actual artículo noveno.

\footnotetext{
4 Historia de la ley 19.968 que crea los Tribunales de Familia, segundo informe Comisión de Constitución, discusión en particular (Valparaíso, 2004) p. 1057. Disponible en: http:// www.bcn.cl/histley/lfs/hdl-19968/HL19968.pdf, consultada el 28 de agosto de 2015. Turner Saelzer, Susan (2002) "Los tribunales de familia". Revista Ius et Praxis, Vol. 2, $\mathrm{N}^{\circ} 8$, pp. 413-443.

6 Historia de la ley 19.968 que crea los Tribunales de Familia, segundo informe Comisión de Constitución, discusión en particular (Valparaíso, 2004) p. 1057, disponible en: http:// www.bcn.cl/histley/lfs/hdl-19968/HL19968.pdf.
} 
Pese a lo anterior, indicios pesquisados en la jurisprudencia ${ }^{7}$ y la práctica de los tribunales ${ }^{8}$ dieron cuenta que algunos jueces, la mayoría de la muestra del examen aplicado dado a conocer aquí, extiende la aplicación del instituto a aquellos sectores donde el legislador determinó que el juez no podía ingresar. Por ejemplo, uno de los sentidos pesquisados en la práctica9 ${ }^{9}$ se produce cuando un juez, en uso del que estima es el principio de la desformalizacion, consiente que se conteste una demanda en audiencia preparatoria, en circunstancias que la ley imperativamente solo permite hacerlo 5 días antes de la misma. Lo anterior se conecta con el valor y alcance actual de los principios jurídicos en el sistema de derecho que será examinado al final ${ }^{10}$. Por lo pronto vale decir que sobre ellos no

7 Un fallo reciente de la Corte de Apelaciones de San Miguel se refiere a la desformalización como un principio y le da un alcance práctico singular. Una demandada no contestó en tiempo y forma la demanda, y por ende no pudo reconvenir. Es decir, 5 días antes de la audiencia preparatoria. La misma parte solicita la casación en la forma ya que señala que según su opinión pudo pedir compensación económica igualmente en la audiencia preparatoria, verbalmente, sin previamente haber deducido contestación escrita. La jueza de la instancia estimó precluido su derecho, atendido el claro tenor de la norma que fija la oportunidad procesal para desarrollar dicha actuación. La Corte señala que en estos casos es posible soslayar el plazo y las formas establecidas por el legislador, por el aludido principio. Lo expone de la siguiente manera: "cabe señalar que la exigencia de contestar la demanda por escrito y con anticipación a la audiencia es una medida de ordenamiento de la litis, que hace excepción a los principios de oralidad y desformalización que informan el procedimiento en materia de familia, debiendo estos prevalecer en caso de situaciones como la de la especia, en que tales medidas ordenatorias pueden redundar en privación de derechos de alguna de las partes". CORTE DE ApELACiOnes de SAN Miguel. 23 de marzo de 2016. Rol No 879-2015.

Los fallos que se citan a continuación expresan literalmente que la desformalización es un principio jurídico y cada uno de ellos le da una aplicación particular. Véase: Corte de Apelaciones de Valparaíso. Rol N³75-2008 (Repertorio, 2010, p. 662); Corte de Apelaciones de Santiago. 17 de marzo de 1999. Rol No 4331-1998. Disponible en ID LegalPublishing 20677; Corte de Apelaciones de Puerto Montt. 30 de agosto de 2010. Disponible en ID LegalPublishing 47003; Corte de Apelaciones de San Miguel. 4 de octubre de 2010. Rol No 415-2010. Disponible en ID Westlaw Chile CL/ JUR/8075/2010; Corte de Apelaciones de San Miguel. 10 de octubre de 2010. Rol N ${ }^{\circ}$ 218-2010. Disponible en ID Westlaw Chile CL/JUR/2564/2010; Corte de Apelaciones De Concepción. 22 de abril de 2010. Rol No 433-2009. Disponible en ID Westlaw Chile, CL/JUR/2746/2010; Corte de Apelaciones de Concepción. 28 de agosto de 2009. Rol $\mathrm{N}^{\circ}$ 2239-2008. Disponible en ID Westlaw Chile, CL/JUR/667/2009; Corte de ApelaCioNes de Valparaíso. 9 de octubre de 2008. Rol N³75-2008. Disponible en ID Westlaw Chile, Cl/JUR/3744/2008; Corte de Apelaciones de Punta Arenas. 10 de diciembre de 2007. Rol N 79-2007. Disponible en ID Westlaw Chile, CL/JUR/251/2007; Corte de Apelaciones de Santiago. 30 de octubre de 2007. Rol N²916-2007. Disponible en ID Westlaw Chile CL/JUR/121/2007; Ayala con Trejo (2010): Corte De Apelaciones De SAN Miguel. 10 de mayo de 2010 (alimentos). Rol N²18-2010, ID LegalPublishing: CL/ JUR/2564/2010.

8 Esto es precisamente lo que se verá infra en el capítulo concerniente a los resultados de estudio aplicado.

$9 \quad$ Véase anexo, apartado 2.4.

10 Cap. 4. 
hay acuerdo en sus alcances teórico prácticos ${ }^{11}$, y es posible que esas dudas se trasladen a los jueces examinados.

El presente análisis postula que, al igual que la correcta interpretación de la norma acorde con su intención manifestada en su historiografía, no estamos frente a una directriz jurídica sino que ante una característica preanunciada dentro del plexo normativo, que no confiere ningún tipo de operatividad autónoma al juez. Entre otras razones porque darle ese carácter no solo controvierte su sana interpretación, sino que produce ingentes consecuencias prácticas que afectan la seguridad jurídica y el derecho de los justiciables a la certeza y previsibilidad en las decisiones de los tribunales ${ }^{12}$.

\section{2) CUESTIÓN PREVIA: ALCANCES DE LA ATRIBUCIÓN DEL ARTÍCULO 27 DE LA LEY 19.968 VERSUS LOS ALCANCES DE LA DESFORMALIZACIÓN}

El antecedente legislativo inmediato del artículo 27 de la ley 19.968, que es donde se contienen los poderes otorgados al juez de familia que es necesario confrontar con el instituto objeto de esta pesquisa, fue el artículo 19 del proyecto. La disposición señalaba: "En silencio de la ley, el juez determinará la forma como se verificarán las actuaciones, y en esta tarea como en la de interpretar las normas del procedimiento, tendrá siempre presente que su objeto es la efectividad de los derechos reconocidos por la ley sustancial y la mejor y más pronta decisión de la controversia"13.

Luego el contenido de la actual disposición quedó como sigue:

Artículo 27.- Normas supletorias. En todo lo no regulado por esta ley, serán aplicables las disposiciones comunes a todo procedimiento establecidas en el Código de Procedimiento Civil, a menos que ellas resulten incompatibles con la naturaleza de los procedimientos que esta ley establece, particularmente en lo relativo a la exigencia de oralidad. En dicho caso, el juez dispondrá la forma en que se practicará la actuación.

Como se observa, los alcances de la norma antecedente eran similares a la actual, solo que no se extendía la supletoriedad a las reglas del actual Código de Procedimiento Civil. Lo singular era la guía a la labor interpretativa del juez sobre el orden adjetivo, que considera la primacía de

\footnotetext{
11 Guastini, Riccardo (2013) Distinguendo Ancora. Madrid: Marcial Pons, pp. 34- 36. Alpa, Guido (2006) I principi generali. (Segunda Edición). Milano: Giuffrè Editore, p. 7.

12 CARretta (2014) 481-495.

13 Historia de la Ley $\mathrm{N}^{\circ} 19.968$ de 2004. Disponible en: http://www.bcn.cl/histley/lfs/hdl19968/HL19968.pdf, [fecha de visita 28 de agosto de 2015], p. 116.
} 
los objetivos del derecho sustancial y la rapidez. Durante su discusión, la Comisión unánimemente acordó sustituir lo expresado en la última parte de la disposición, por lo siguiente: "su objetivo es el adecuado resguardo de los derechos reconocidos por la ley y la más pronta y justa decisión de la controversia" 14 .

La similitud entre las facultades entregadas al juez en la norma que se viene señalando, con la de flexibilizar u omitir trámites, que es a lo que alude la idea de la desformalización, era tan cercana, que se pretendió subsumir ambas dentro de un mismo parágrafo. En efecto, con la indicación sustitutiva del Ejecutivo al proyecto de ley, el contenido del artículo originalmente propuesto (artículo 19) quedó contenido en el artículo 10, bajo el epígrafe de "desformalización". Sin embargo, esta norma en definitiva fue rechazada en la discusión legislativa pues hubo temor, por parte de los parlamentarios, de otorgar facultades al juez para crear trámites o actuaciones procesales al margen de la ley ${ }^{15}$. Por una parte, la idea del Legislativo en toda la discusión parlamentaria sobre este punto era no promover la posibilidad de un juez legislador y, por la otra, acotar este mecanismo, para que solo, luego de haber indagado reflexivamente el juez algún tipo de solución en el CPC, opte por aplicar una forma novedosa de actuación. Siempre y cuando aquella tenga como finalidad resguardar la oralidad que inspira el procedimiento. No se trata de una actuación al margen de la ley sino por el contrario una facultad legal de ultima ratio. Es por ello que no debe estimarse que esta norma, por lo menos desde el punto de vista textual, es una manifestación de la desformalización.

Pese a lo anterior, los jueces de familia chilenos consultados no se han encontrado en la disyuntiva de no encontrar formas para la ejecución de un acto ${ }^{16}$. Ello puede deberse al amplio catálogo de trámites contenidos en la LTF que por sí mismos son flexibles, y a la supletoriedad del CPC, que abre un amplio abanico de posibilidades. No obstante, una sentencia de la Corte de Apelaciones de San Miguel, recaída sobre un recurso de apelación deducido en contra de una resolución que no dio lugar a la solicitud de remitir nuevos oficios, a fijar nuevo día y hora, y a decretar una medida de retención legal de bienes sobre dineros que recibiría el demandado por concepto de desahucio, señaló respecto a la facultad establecida en el artículo 27: “...el juez puede aplicar supletoriamente las disposiciones comunes a todo procedimiento establecidas en el Código de Enjui-

\footnotetext{
14 Historia de la Ley $\mathrm{N}^{\circ} 19.968$ de 2004. Disponible en: http://www.bcn.cl/histley/lfs/hdl19968/HL19968.pdf, [fecha de visita 28 de agosto de 2015], p. 116.

15 Carretta (2014) 489-490.

16 En este punto casi ningún entrevistado recuerda haber hecho uso de la facultad en comento.
} 
ciamiento Civil, salvo que ello signifique vulnerar los principios que inspiran el procedimiento ante los tribunales de familia, en cuyo caso queda facultado para disponer la actuación de la forma como él lo estime pertinente. En otras palabras, por la citada disposición legal se está facultando al juez a que por via jurisdiccional cree derecho procedimental, sin perjuicio de la actuación de oficio del cual también está investido"17.

Si bien el tribunal estimó que el artículo 27 de la LTF facultó al juez para crear por vía jurisdiccional derecho procedimental, por las razones que se han venido exponiendo, tal decisión no encuentra ningún correlato con la génesis y los objetivos que dicha norma posee. Tampoco con las consecuencias de tal interpretación. La creación de normas de orden público, más allá de que es una función que está reservada exclusivamente al Congreso, no puede ser dejada a los jueces, sin poner en grave riesgo a la seguridad jurídica.

\section{3) RESULTADOS DEL ESTUDIO APLICADO}

\section{(3.1.) DESCRIPCIÓN DEL MARCO METODOLÓGICO}

Esta prospección se nutre de la información recogida en entrevistas personales semiestructuradas realizadas a 27 jueces de familia. Se tomaron muestras en diversas regiones del país, para cotejar una mayor amplitud de la realidad nacional, previendo que las características geográficas pueden influir en los resultados, pero su incidencia ha sido residual y se ha enfocado sobre un punto auxiliar ${ }^{18}$. Las entrevistas han sido tomadas personalmente por el suscrito. La elaboración de las preguntas y el lineamiento de los parámetros de valoración fueron hechas por el suscrito y el antropólogo social Marcelo Barría Bahamondes. Este último a su vez ha procedido al análisis de texturas dentro de la perspectiva de su profesión, bajo la dirección del investigador a cargo quien luego procedió al examen y valoración jurídica de los lineamientos atingentes a las hipótesis por las que se articulan los resultados presentados aquí. Teniendo en cuenta su contexto, el objetivo del análisis y la inferencia o deducción que emana de ellas. Los instrumentos de observación y metodología utilizados cuenta con la aprobación y certificación ética para el trabajo con humanos del

Ayala con Trejo. Rol No 218-2010 considerando $8^{\circ}$.

18 Se refiere al cumplimiento de las pensiones alimenticias y los métodos que los magistrados utilizan para su cumplimiento. En las regiones limítrofes, Arica y Punta Arenas, resulta más efectivo el arraigo que las órdenes de arresto, atendido el alto desplazamiento que manifiestan los habitantes de dichas zonas hacia Perú, Bolivia y Argentina. 
comité de bioética de la Pontificia Universidad Católica de Valparaíso. Toda la información e insumos suministrados por las encuestas anónimas se encuentran bajo custodia del investigador responsable.

Es bueno insistir que el total de jueces de familia de la muestra, no definen un quantum representativo. No es este un estudio estadístico y esto debe ser resaltado, porque el lector no verá una cuantificación de la realidad judicial. Se trata de un análisis cualitativo que, conforme a esa calidad, hace posible visibilizar un horizonte que engloba una serie de situaciones y discursos que arrojan ciertos datos recolectados en entrevistas, por los que es posible vislumbrar la manera en que piensan en general los jueces, y a su vez, presumir las razones por las cuales toman las decisiones que toman.

Se agrega como anexo el análisis primario de la información bruta recogida en las entrevistas. Su mayor extensión se justifica porque contiene el detalle de la metodología utilizada y se transcriben varias opiniones que se consideraron relevantes para llegar a los resultados que se exhiben ahora. El texto que se presenta, pretende constituirse como el producto refinado de la observación primaria.

\section{(3.2.) Precisiones iniCiales y Despeje de INFORMaCión}

De acuerdo al análisis de campo, es posible sacar varias conclusiones sobre la interpretación/aplicación que el grupo de jueces analizados hacen del artículo 9 de la LTF.

Los prototipos de interrogación van desde lo general y teórico, a lo particular, a través de preguntas atingentes a los usos prácticos que, en virtud del entendimiento particular del instituto, realizan los jueces para el manejo del litigio. El perfil de entrevistas se contornea a través de una pregunta abierta y concreta, que busca pesquisar un resultado cuantitativo: ¿qué es la desformalización?: el 51, 8 \% respondió que se trata de un principio jurídico ${ }^{19}$. Los matices de la respuesta serán expuestos más adelante. Todos los detalles de los insumos utilizados, preguntas específicas realizadas y gráficos que se desprenden de la prospección en terreno, están en el anexo.

Si se pueden sintetizar todas las ideas expresadas por los jueces examinados, la idea de la desformalización ${ }^{20}$ se percibe por ellos prima facie como

\footnotetext{
19 Esto está en consonancia con la jurisprudencia que se ha dictado sobre el tópico. CARRETTA Muñoz (2014) 490-492.

20 En este punto se pidió a los entrevistados que evocarán a la desformalización de acuerdo al sentido común.
} 
un canal de fluidez por donde las riendas del rito procesal se pueden manejar con mayor libertad, en aras a responder con rapidez y eficiencia a las demandas que se les plantean habitualmente. En este sentido se especifica el criterio dado a conocer por ellos en cinco percepciones: (I) mayor libertad para fallar sin apego al ritual, (II) las exigencias administrativas son prescindibles, (III) celeridad y fluidez del proceso, (IV) flexibilidad y adaptabilidad, (V) eficiencia y eficacia de la labor jurisdiccional ${ }^{21}$.

Lo anterior se expresa en la práctica judicial a través de las siguientes actitudes: (I) uso de lenguaje coloquial en la audiencias, (II) mayor horizontalidad entre las partes (todos los intervinientes en juicio), (III) salvaguarda a omisiones en audiencia preparatoria, (VI) omisión del exceso de ritualidad, (V) flexibilidad en las exigencias probatorias, (VI) recepción tardía de pruebas ${ }^{22}$. Los dos primeros puntos se radican en aspectos extra jurídicos que confiere el devenir propio del manejo de las audiencias. Van desde el uso correcto del lenguaje hasta la utilización de vestimenta adecuada. En este nivel ocurre también que los abogados de las partes suelen conversar con los magistrados sobre aspectos relacionados al litigio, antes de la audiencia, sin forma de juicio. También se dan conversaciones sobre otros aspectos de la vida diaria, etcétera.

Todos los convencionalismos que acontecen a la sazón de la oralidad prevista para el desarrollo de este tipo de litigios no pueden ser examinados aquí puesto que pertenecen a un estatuto diverso a la desformaliza-

21 Sobre ello se vertieron opiniones como las que siguen: "(la desformalización) me alude a que tengo que centrarme más en el fondo de la discusión, tratar de resolver el fondo del conflicto juridico, en vez de prestarle mayor atención a incidencias de tipo procedimental o formales". Juez \#2 (véase anexo, apartado 2.1.).

"La desformalización implica desritualización, o sea, no hay rito, no hay ceremonia". Juez \#4(véase anexo, apartado 2.1.)

"...desformalización es que no esté tan atado a las formas y que pueda ser un poco más ágil, que permita fluir de mejor forma los intereses de las partes en este caso...”. Juez \#15 (véase anexo, apartado 2.1).

"... desde el punto de vista del sentido común para mí tiene que ver con eso, que no hay un orden consecutivo expresamente establecido de como se hacen las cosas, hay que hacerlo un poco a la suerte de lo que se vaya dando en el sentido común de la audiencia”. Juez \#21 (véase anexo, apartado 2.1).

22 Sobre el particular: “...yo flexibilizo algunos términos, dependiendo de las personas con las cuales uno está tratando, porque si estoy tratando con personas con abogados particulares no necesito flexiblizar el lenguaje. En eso, en la forma, no exijo a raja tabla o perentorio que un testigo, por ejemplo, pudiera venir un poquito menos formal vestido... ¿Qué otra cosa? A veces por ejemplo me ha bastado con el carnet de conducir porque no tiene el carnet de identidad y nadie duda que es la persona, cosas así. Pero principalmente, (la desformalización se aplica en) poder volver atrás en algunos puntos". Juez \#8 (véase anexo, apartado 2.3).

"...las partes han hecho las observaciones a la prueba, pero el tribunal no ha dado el veredicto y adviertes que hubo un vicio en la audiencia preparatoria, por ejemplo. Tú en virtud de la desformalización podrías citar a una audiencia a las partes para salvar esas omisiones o errores sin anular todo lo obrado en el procedimiento". Juez \#14 (véase anexo, apartado 2.3). 
ción. La cercanía de esta a los tintes propios de la convivencia, encontrada en el catastro de opiniones, deben atribuirse a una ideación e interrelación muy a priori entre ambas concepciones, que se aleja demasiado de los límites jurídicos del instituto. Aquellos pertenecen al campo de la ética y están regulados en el Código Orgánico de Tribunales y otros instrumentos como el auto acordado de la Corte Suprema sobre principios de ética judicial y comisión de ética (acta 262-2007) y el Código Iberoamericano de Ética Judicial ${ }^{23}$ que se aplica supletoriamente al acta.

La pesquisa arrojó que una gran cantidad de dificultades con la aplicación/interpretación del instituto en referencia se ocasiona en la audiencia preparatoria. Ello se coordina con el hecho que es en esta, en la que existe un mayor número de fases y que, en determinadas circunstancias, puede producirse repentinamente en su desarrollo o inicio, el cierre de todo el proceso. Lo anterior, porque los intervinientes en un número no menor de causas llegan a acuerdo en ella, o se produce el abandono del procedimiento en el caso que el demandante no se presente. En aquel panorama, el estudio que se presenta a continuación analiza tres ejes problemáticos dentro de la mencionada instancia ${ }^{24}$.

\section{(3.3.) LA POSIbILIDAd DE DiCTAR SENTENCIA EN AUdiENCiA PREPARATORIA}

La audiencia preparatoria es aquella en que las partes ratifican sus presentaciones y primordialmente ofrecen las pruebas que luego serán incorporadas a la audiencia de juicio. En esta etapa el juez juega un papel primordial, pues deberá limpiar el pleito de todo vicio de nulidad, alegación o prueba impertinente o sobreabundante y resolver las cuestiones accesorias que se presenten. También la LTF prevé (artículo 61) la posibilidad que se dicte sentencia en la misma audiencia si ambas partes están de acuerdo. Sin embargo, se han establecido ciertos usos en base ${ }^{25}$,

23 Ver Artículos 7, 8 y 9. Disponible en: http: //www.tsjbaires.gov.ar/ciej/sites/default/files/ axiologicos/CIEJ_reformado_2014.pdf, [fecha de visita 28 de agosto de 2015].

24 Tenga en cuenta el lector que las entrevistas versan sobre una serie de aspectos que directa o indirectamente dicen relación con la desformalización. De toda la abundante información recopilada, hubo que discriminar aquellos que son principales, de otros auxiliares. Los que se mencionan en el texto son solo aquellos que se consideraron mayormente atingentes. Profundizar en todos conspira contra cualquier norma editorial para este tipo de artículos por una parte, y por la otra, el lector podría perder de vista el objetivo esencial del estudio: ejemplificar los inconvenientes que existen en la judicatura cuando esta estima que la desformalización es un principio en circunstancias que no lo es, y no describir cada uno de los pormenores que se suceden a propósito de la desformalización.

25 Esto se explica entre otras cosas por los instructivos emanados del máximo tribunal. La Corte Suprema, dentro de sus facultades económicas, suele dictar autos acordados o "actas" 
en parte a la desformalización y en parte al principio de oficialidad, por los cuales los magistrados, cuando el litigio es de baja intensidad, dictan sentencia de inmediato sin exigir la comparecencia del demandado a dicha audiencia preliminar. La baja intensidad significa que la posibilidad únicamente se gesta en materias donde, estando válidamente notificado el demandado, no se requiere un gran margen probatorio y la causa de pedir está sujeta a un estatuto mayormente presuntivo, como el caso de los alimentos cuando lo solicitado es el mínimo legal ${ }^{26}$. Como en esta alternativa se produce cierta tirantez en el respeto a las reglas del debido proceso -bilateralidad de la audiencia-, la mayoría de los jueces pesquisados son reacios y derechamente no optan por esta alternativa; pero un buen número de ellos atienden a las posibles ventajas. Como lo son la existencia de un ahorro de tiempo y costos para el Estado y el justiciable que en este tipo de juicios se considera en desigualdad.

Los juicios de alimentos son los de mayor ocurrencia dentro de las diversas materias que se tramitan en un tribunal de familia ${ }^{27}$ por lo que su rápido término se traduce en una buena gestión administrativa que descongestiona la carga de trabajo, en beneficio de causas complejas. La exigencia probatoria para el actor es precaria y se sustenta básicamente en los elementos que legitiman la acción: el acta de nacimiento o matrimonio. A falta de prueba en contrario, la ley presume que el alimentante está en condiciones de otorgarlos y que el alimentario requiere a lo menos el $40 \%$ de un ingreso mínimo mensual para subsistir ${ }^{28}$. La ausencia del demandado cierra los elementos necesarios para sustentar un juicio adecuado, puesto que es de él la carga probatoria necesaria para destruir las inferencias que le juegan en contra. Por otra parte, el escaso valor de

que contienen una serie de instrucciones relacionadas a la tramitación de causas por parte de los tribunales de familia. Ello ha causado gran polémica en la judicatura, porque a nivel gremial es visto como una intromisión indebida en la competencia que la ley le otorga a los jueces, de materias reguladas (procedimientos) expresamente por la ley. Una de ellas, el auto acordado sobre administración y gestión de los tribunales de familia (acta 98 - 2009) sugiere a los magistrados la rotación de funciones, la no radicación de causas en manos de un magistrado, la tipología de casos y se insta a favorecer el término del litigio en la primera audiencia. Sobre el particular véase la declaración presentada por el Directorio de la Asociación de Magistrados de Chile el año 2014, que se tradujo en una presentación formal ante el pleno de la Corte Suprema. Disponible en: http://www.magistradosdechile.cl/,http:// www.magistrados.cl/asociacion-de-magistrados-hace-historica-presentacion-ante-cortesuprem/, [fecha de visita 28 de agosto de 2015].

Art. 3 y 7 de la Ley $\mathrm{N}^{\circ} 14.908$ de 1962 , sobre abandono de familia y pago de pensiones alimenticias, y arts. 323, 329, 330 y 332 del Código Civil.

$27 \quad 32,3 \%$ según información oficial. Véase Anuario estadístico sobre la Justicia de Familia 2012 del Ministerio de Justica. Disponible en: http://historico.minjusticia.gob.cl/media/2014/05/Anuario-Familia-2012-Final.pdf [fecha de visita 28 de agosto de 2015], p. 15. Artículo $3^{\circ}$ de la Ley $N^{\circ} 14.908$ de 1962. 
la cosa juzgada en estos juicios no cierra la posibilidad de demandar una modificación de su monto por el litigante ausente si queda disconforme y no deduce apelación oportunamente.

La desventaja es que no existe norma legal que permita dictar sentencia en la audiencia preparatoria en las circunstancias antes dichas. Si el argumento es la desformalización que, como principio del Derecho, lo permite, en este caso se está forzando incluso más allá de los límites que, como directriz jurídica, estiman corresponderle aquellos que le otorgan una superficie mayor de aplicación ${ }^{29}$. En este sentido, no hay lagunas, ni dificultades interpretativas en el claro tenor de las normas que discurren sobre el particular ${ }^{30}$. El proceso ordinario de cognición en los tribunales de familia, se sustenta sobre dos audiencias que poseen propósitos bien determinados. La preparatoria busca el filtro de todo el material impertinente que los contendientes ofrecen, pero además da la oportunidad al demandado de oponer excepciones y presentar pruebas. La audiencia de juicio, por su parte, conlleva la labor jurisdiccional más importante: dictar sentencia. Todo lo anterior en consonancia al derecho a la tutela judicial efectiva que a las partes les asiste en el desarrollo del procedimiento ${ }^{31}$.

Por otro lado, el principio de oficialidad que también se utiliza como fundamento, como ya se dijo, tampoco puede constituirse como la fuente que habilita legalmente para tomar la alternativa en comento. Está previsto en el artículo $9^{\circ}$ de la LTF, y explicitado en el artículo 13 en el siguiente tenor: "Artículo $13^{\circ}$. - Actuación de oficio. Promovido el proceso y en cualquier estado del mismo, el juez deberá adoptar de oficio todas las medidas necesarias para llevarlo a término con la mayor celeridad. Este principio deberá observarse especialmente respecto de medidas destinadas a otorgar protección a los niños, niñas y adolescentes y a las victimas de violencia intrafamiliar. Asimismo, el juez deberá dar curso progresivo al procedimiento, salvando los errores formales y omisiones susceptibles de ser subsanados, pudiendo también solicitar a las partes los antecedentes necesarios para la debida tramitación y fallo de la causa".

Lo primero que se puede apreciar es que la norma es coherente con los poderes que el ordenamiento le concede al juez de familia tanto en los

\footnotetext{
29 Carretta (2014) 485-487.

$30 \quad$ Artículos 61 a 67 de la Ley N 19.980 de 2004.

31 De acuerdo a lo resuelto por el Tribunal Constitucional: "conjunto valórico normativo que configura la tutela judicial efectiva... según se desprende de los artículos 1, 5, 6 y 19, números 2, 3 y 26 de la Carta fundamental." Véase la sentencia del Tribunal Constitucional. Universidad Alberto Hurtado (2011) Rol N 1876-2011.
} 
expedientes por medida de protección, como en los referentes a la violencia doméstica. En ambos hay mecanismos específicos que permiten detener la tramitación en la primera audiencia con el fin de darle término con la rapidez requerida. En el primer caso, a través de la facultad que le confiere el artículo 71 inciso $4^{\circ}$ de la LTF de dictar sentencia inmediata en la audiencia preliminar si se cuenta con todos los antecedentes necesarios para hacerlo y, en el segundo, de suspender condicionalmente la dictación de la sentencia si se reúnen las condiciones exigidas por el artículo 96. En cuanto al procedimiento ordinario, la concordancia con el contenido de la oficialidad se aprecia en las alternativas que la LTF contiene para que este se lleve a término sin dilaciones y por iniciativa judicial. La facultad de controlar la admisibilidad de las demandas (54-1 LTF) y la conciliación que debe promover en las audiencias (61 n 5 LTF), son prueba de ello. En este orden de ideas la ley, por este genuino principio, no ha querido dotar al juez de herramientas fuera de ella. Ello sería contradictorio con la armonía de las normas que detallan las potestades señaladas y, aun peor, entraría en conflicto con la prohibición que ella misma predica a nivel constitucional: que los funcionarios públicos no pueden actuar fuera de su competencia, ni menos de una forma distinta a la prevista por la misma ley ${ }^{32}$.

\section{(3.4.) POSibilidad DE CONTESTAR LA DEMANDA EN AUdiENCiA PREPARATORIA}

El artículo 58 de la LTF prescribe que en el juicio ordinario la contestación de la demanda solo puede efectuarse antes de los cinco días previos a la audiencia preparatoria. Sobre este punto, si bien el discurso oficial de los entrevistados fue procurar el cumplimiento del plazo de acuerdo a lo establecido por la ley ${ }^{33}$, confrontados a la posibilidad de que a la audiencia concurriera un demandado visiblemente carente de recursos que no contestó en tiempo y forma, ni se procuró una defensa letrada, algunos abrieron la posibilidad de contestación, contra lo señalado

Véase artículos 6 y 7 de la Constitución Política de la República.

"No (lo permito) por ningún motivo, porque la ley establece claramente los plazos de contestación... la desformalización, esta flexibilidad no se da para beneficiar a ninguna de las partes, la flexibilidad se da para facilitar el proceso, el término de la causa, por lo tanto debe haber certeza juridica para todas las partes y el proceso no puede quedar en manos de una de las partes... por lo tanto si tú lo permites, el proceso (podría quedar) en manos del demandado y el demandante queda ahi absolutamente en desventaja”. Juez \#14 (véase anexo, apartado 2.4.). 
perentoriamente por la disposición legal ${ }^{34}$. Los matices fueron que en ese caso se decreta la suspensión de la audiencia, fuera de las circunstancias que autoriza la ley ${ }^{35}$, para que la parte se procure de asistencia jurídica y solo en aquellas materias donde el demandado puede verse mayormente desfavorecido ${ }^{36}$. En el fondo esto implica abrir un nuevo plazo de contestación. En ese sentido, un caso repetitivo fue en las demandas de divorcio en que no se solicitó compensación económica en tiempo y forma y la parte manifiesta expresamente su deseo de accionar. Según algunos, la desformalización, en tanto principio normativo, permite motivar oficiosamente la suspensión de la audiencia. Pero lo que más llama la atención fue que el contenido que se le asignó al instituto en comento para obrar de esa manera fue reconducido a la equidad y dentro de ella al principio del derecho civil de la protección del cónyuge más débil. En el fondo, la amalgama entre todos los conceptos y la dificultad de determinar sobre todo el contenido de la "equidad", se pueden traducir como las consabidas razones de justicia material que habitualmente esgrimen los jueces cuando hacen uso, inconsciente o no, de su tradición de cultura ${ }^{37}$ y sus sentimientos fuera del orden jurídico. Pero aquello se sale de los lineamientos de esta prospección ${ }^{38}$. En lo concerniente a ellos, la desformalización en estos casos jugó praeter legem, como un argumento jurídico para crear dos trámites no contemplados en la ley: la contestación de la demanda en la audiencia preparatoria y la comparecencia en aparente indefensión del demandado como causa de suspensión de la audiencia. En ambos casos, aparte del defecto legal anotado, se infringe abiertamente

34 Por ejemplo: "En casos de compensación económica yo sí permitiría contestar en la audiencia, porque es un caso especial. Ahora en otros casos no permitiría contestar, si veo a una persona que está deprivada socioculturalmente, o bien a mis ojos por la pura percepción, inmediación, presenta algún problema para expresarse, bueno, entonces en ese momento pensaría en suspender la audiencia y por el principio del derecho a la defensa, a la debida defensa, le designaría un abogado". Juez \#22 (véase anexo, apartado 2.4.).

35 El artículo 20 de la Ley $\mathrm{N}^{\circ} 19.968$ de 2004, solo autoriza la suspensión de la audiencia, a instancia y previo acuerdo de las partes, hasta por dos veces.

36 En todas las otras materias ordinarias que se presentan en un tribunal de familia la mayoría de los entrevistados no encuentra motivos para la suspensión fuera de las causales que la ley señala.

37 En el sentido que al concepto le otorga el realismo jurídico, el juez como un ser humano cualquiera inserto en la sociedad es, durante el transcurso de su vida, permeado de una serie de factores familiares, político, religioso y de toda índole. Es natural entonces que en sus juicios algo de ese acervo cultural esté presente. De acuerdo a lo que Ross señala: el juez es un "fenómeno cultural". Ross, Alf (1959) On law and Justice: New Yersey Clark, pp. 99-100.

38 Este criterio muy conectado a la intuición es inseguro pues se basa en una mera percepción del juez en audiencia. Esto abre la puerta al extenso y dificultoso tema de la discrecionalidad del juez. Véase: BaraK, Aharon (1995) La discrezionalità del giudice. Milano: Giuffrè Editore, pp. $13-16$. 
la preclusión al revivir un plazo que se agotó por no haberse ejecutado el acto dentro de su transcurso ${ }^{39}$.

No obstante todo lo anterior, un menor número de jueces se mantuvo por un apego irrestricto a las condiciones impuestas por la norma, sin importar la aparente ${ }^{40}$ calidad de los justiciables.

\section{(3.5.) LA INCIDENCIA DE LA DESFORMALIZACIÓN EN EL DESARROLLO SECUENCIAL DE LA AUDIENCIA PREPARATORIA: CONFRONTE CON LA PRECLUSIÓN}

Como primera observación general hay que decir que la preclusión ${ }^{41}$ como instrumento útil para la secuencia de actos del proceso no ha sido derogada ni expresa ni tácitamente por la LTF. Por el contrario, está plenamente vigente de acuerdo a la supletoriedad que asume el Código de Procedimiento Civil. Pero la eficacia del instituto choca con algunas apreciaciones que los jueces examinados han tenido sobre ella, directa o indirectamente. Muchos estiman que es posible, por ejemplo, permitir la presentación u objeción de prueba, luego de que la fase para hacerlo se cierra $^{42 .}$

Si bien los instantes de apertura y cierre de etapas en el difuso margen de la oralidad no son tan definidos como en un procedimiento escrito, la LTF sí los ha previsto y son reconocibles en el desarrollo de la audiencia preparatoria. Se identifican: discusión y prueba. Su conformación

39 Sobre ello se volverá en el párrafo siguiente.

40 Se debe tener presente que es imposible saber con precisión cuál es la calidad social o cultural de una persona si se le observa por no más de 10 minutos. De ahí que este tipo de apreciaciones resulte feble.

41 Entendida la preclusión procesal no solo como la pérdida, extinción o consumación de una facultad procesal que se produce por el hecho de haberse ejercitado, por no haberse observado el orden asignado por la ley para su ejercicio, o por haberse cumplido junto a una actividad incompatible con su uso, sino también como un bien social para que la vida en comunidad se desarrolle de manera segura y pacífica. Desde este vértice puede ser vista como la base de la cosa juzgada. De SANTIS, Francesco (2005) "Riforme processuale e "disponibilità" del regime preclusivo". Rivista Studi di Diritto Civile in Onore di Giuseppe Tarzia. Milano, Italia: Giuffrè, pp. 2641-2642.

42 "Es que creo que la preclusión en un procedimiento oral y desformalizado no es tan estricta, no es tan absoluta". Juez \#15 (véase anexo, apartado 2.5.).

"Yo en general trato de marcar los tiempos, pero también debo reconocer que si llega a suceder una situación como esa en que se le olvidó una prueba, le doy la opción a la contraria, le pregunto ‘Hay algún inconveniente?'. Si la contraria no tiene inconveniente la acepto. Si la contraria se opone, entiendo queda cerrada la posibilidad". Juez \#20 (véase anexo, apartado 2.5.).

"P: ¿Es posible en virtud de la desformalización omitir la preclusión de esas etapas (procesales)?

$R: Y o$ lo he hecho, pero dando traslado. Si la otra parte no tiene ningún inconveniente, que generalmente no lo tienen, si lo acepto”. Juez \# 23 (véase anexo, apartado 2.5.). 
señalada en el artículo 61, que también se remite a las fases de la audiencia de juicio, prevé un orden lógico consecutivo de 10 períodos. Incluso dentro de ellos se identifican subfases. Por ejemplo, el artículo 31 establece un orden previo a la resolución de excluir prueba. El juez tiene que primero estudiar la admisibilidad, resolver las convenciones probatorias y luego escuchar a las partes para poder resolver. La ley previó este orden no azarosamente sino que ha correspondido a una finalidad, inherente del derecho procesal: el orden y la certeza en la forma de solución de los conflictos humanos.

Entonces, luego de la etapa de discusión comienza la de prueba, con la fijación de los hechos sobre los que se va a rendir, luego se ofrecen, se discute su exclusión, se rinde excepcionalmente y se cierra con la interlocutoria que fija todo lo acontecido hasta ese momento y cita a juicio. Si se permite que una parte ofrezca prueba o discuta sobre ella una vez que el juez ha dictado la mencionada resolución, queda mermado el derecho del otro interviniente a objetarla o a contradecir, infringiéndose en consecuencia el debido proceso. Esto no cambia en demasía si el tribunal abre lugar a un incidente para resolver la presentación extemporánea, puesto que ya desde su conformación tal posibilidad nace viciada. Al juez le está prohibido por vía incidental revivir un lapso fenecido pues le afecta el desasimiento. Cabe recordar que la resolución que cita a juicio es a todas luces una sentencia interlocutoria. En este mismo sentido tal como a las partes, al juez le afecta la preclusión. Esta es la denominada preclusión proiudicatio $^{43}$, que le impide revisar situaciones anteriormente resueltas fuera de los casos expresamente previstos en la ley.

Una segunda observación, ahora particular, confronta dichas actuaciones con la impronta de un instituto presente en el estudio del derecho procesal desde sus albores ${ }^{44}$, que pertenece no solo en el sistema continental, sino que también a los ordenamientos de tradición jurídica anglosajona ${ }^{45}$. En el lenguaje común evoca la idea de "impedimento" y en su faz funcional sirve para mitigar la lentitud de los procesos. De no preceder las partes podrían volver sobre etapas caducas y la demora sería indefinida. De esta manera su importancia es esencial porque de lo con-

\footnotetext{
43 Redenti, Enrico (1957) Diritto processuale civile. Milano: Giuffrè. Vol. 1, pp. 70-71.

44 Tesoriere, Giovanni (1983) Contributo allo studio delle preclusioni nel proceso civile. Padova: Cedam, pp. 25-51; Chiovenda, Giussepe (1960) Istituzioni di diritto processuale civile. Napoli: Eugenio Jovene Editore. Vol. 1, pp. 319-331.

45 Bone, Robert (2003) Civil procedure, The economics of civil procedure. New York: Fundation Press, pp. 232-259.
} 
trario ningún proceso llegaría a su conclusión. Es por ello que algunos autores consideran que la máxima preclusión se produce en la sentencia definitiva, a través de la cosa juzgada material ${ }^{46}$. Su valor ${ }^{47}$ no se detiene solamente en el plano teórico expresado hasta ahora, sino que posee alcances de jerarquía constitucional. Su infracción transgrede el derecho fundamental que tiene todo ser humano a ser juzgado dentro de un plazo razonable comprendida en el artículo 19 No 3 inciso quinto de la Carta fundamental y en forma explícita en el artículo $8^{\circ}$ de la convención americana sobre derechos humanos ${ }^{48}$.

\section{4) LA DESFORMALIZACIÓN NO ES UN PRINCIPIO JURÍDICO}

Se expone por algunos juristas que los principios pueden constituirse en normas jurídicas de carácter general, que por vía inductiva emanan de un sistema de reglas o leyes que regulan un determinado ámbito social ${ }^{49}$. También se identifican con aquellos paradigmas ubicuos que se estiman como correctos en una sociedad, tales como aquellos relacionados a una exigencia de la justicia, la equidad o alguna otra dimensión de la mora$\operatorname{lidad}^{50}$. Sin embargo, desde aquel vértice valorativo, su categorización resulta especialmente compleja, puesto que no puede constatarse con exactitud en el enunciado de las normas que parecen predicarlos ${ }^{51}$. Es por ello que también se asocian a la vaguedad de aquellas, en tanto se apartan de su contenido de un modo pre o metajurídico.

De acuerdo a las razones expresadas en el marco introductorio de este estudio, el legislador chileno nunca pretendió erigir a la desformalización como un principio jurídico. Dicha elección no fue azarosa, sino que se puede presumir que previó las dificultades de tomar tal decisión. Ello,

Luiso, Francesco (2007) Diritto processuale civile. Milano: Giuffrè, p. 175; Sassani, Bruno (1988) Impugnativa dell' atto e disciplina del rapporto. Padova: Cedam, p. 162.

47 Monteleone, Girolamo (2008) Preclusioni e Giusto processo: due concetti incompatibili. En BongiorNo, Girolamo (Ed.) Studi in onore di Carmine Punzi, Torino: Giappichelli, pp. 413-422.

Si bien los autores que comentan esta garantía hacen alusión al proceso penal, no se ven razones para que no sea extensible al proceso civil y con mayor razón al de familia si la tutela de los derechos en juego, posee igual o mayor importancia que los que se cautelan en la persecución criminal.

49 Alpa (2006) 7.

50 Dworkin, Ronald (2013) Talking Rights Seriously. London: Bloombsbury, p. 46.

51 Tales como aquellas que señalan que el comportamiento de las partes en un proceso no deben infringir ciertas pautas que afectan, por ejemplo, la bilateralidad de la audiencia. De aquellas se constata el valor (principio) de la equidad. MacCormick, Neil (2007) Intitutions of law. Oxford: Oxford University Press, pp. 28-30. 
porque si se considera que la desformalización es un principio jurídico, como la mayoría de los jueces del prototipo dado a conocer, hay que previamente dilucidar una serie de cuestiones complejas relacionadas a ellos. Estas son básicamente tres. Primero, que la formulación de un principio jurídico suele ser ambigua, en ellos hay un notable problema terminológi$\mathrm{co}^{52}$. Cuando se les menciona, son tomados como sinónimos de normas, directrices morales o reglas. El contexto suele direccionarlos hacia alguno de dichos imperativos, pero aquella labor no es fácil y resulta compleja en sí misma y en el hecho que el intérprete también deberá desentrañar con exactitud el alcance de aplicación del imperativo que se trate de acuerdo al contenido de la directriz, lo que acarrea una complejidad mayor. Ello, porque en segundo lugar, son imprecisos, es decir, no hay certeza sobre su contenido $^{53}$ y tampoco hay claridad ni acuerdo sobre cuáles son ${ }^{54}$.

En tercer lugar, su generalidad y falta de tangibilidad, hacen imprecisa su utilidad práctica, y los vincula con rapidez al sentido común. Es posible que el operador se sienta tentado a darle algún efecto jurídico a la idea que el principio está significando, sin mayor reflexión. Como puede advertirse, lo que pasa a continuación, si son varios los operadores que aplican la misma directriz, cada uno con el amplio margen de su creencia, puede producir una aplicación incoherente del principio ${ }^{55}$, con las consecuencias que de ello se sigue. Especialmente en cuanto a las posibles fisuras que puede ocasionarse a la seguridad jurídica ${ }^{56}$.

En síntesis, frente a tantos dilemas y contrariedades que los principios pueden presentar ${ }^{57}$, la elección legislativa resulta ser conveniente. En consecuencia, no puede el juez evocar un principio para solución de un asunto jurídico problemático donde la ley no lo considera. Sucede que los jueces, si actúan así manifiestan una discrecionalidad excesiva, que rebasa los modestos objetivos de la función que tradicionalmente les ha sido encomendada ${ }^{58}$.

Schauer, Frederick (1991) Playing by the rules. Oxford: Clarendon Law Series, pp. 19-24. Luzzati, Claudio (2012) Principi e principi. La genericità nel diritto. Torino: Giappichelli, pp. 4-5.

Guastini (2013) pp. 34-36.

La coherencia es un valor presente en toda la conformación del sistema y estructura del Derecho. Losano, Mario (2002) Sistema e struttura nel diritto, Dalle origini alla Scuola storica. Milano: Giuffrè, p. 197.

Esser, J. (1961) Principio y norma en la elaboración jurisprudencial del derecho privado. Barcelona: Bosch, $498 \mathrm{pp}$.

LuZZATI (2012) 17.

Reclamo que no solo se manifiesta en un sistema continental, también en el common law. Véase: Posner, R. (2008) How judges think. Cambridge: Harvard University Press, pp. 1-15; DwORKIN (2013) 19-34. 


\section{CONCLUSIONES}

1. Lo escueto de la respuesta consignada en la descripción del método señalado supra (3.1), en cuanto a que la mayor parte de los jueces de la muestra consideró que la desformalización se trataba de un principio jurídico, se abre a los relieves que deductiva e implícitamente emanan de las actuaciones judiciales concretas que fueron examinadas.

De esta manera, dentro de la mayoría, se observan jueces que entienden el principio como una técnica interpretativa y otros que la conciben como una fuente normativa. A su vez, se identifican 3 corrientes que se ubican indistintamente en ellos: (I) aquellos que estiman que en virtud de la desformalización pueden actuar libremente para pasar por alto la preclusión o para permitir que se realicen actuaciones fuera del específico rango legal, reforzando la fundamentación a razones periféricas al Derecho, como la justicia material del caso, (II) otro grupo que estima que la desformalización es un principio, pero que en virtud de él no se pueden pasar por alto las reglas establecidas claramente en la ley. En este caso sería una pauta meramente orientativa. (III) Otros que consideran que los poderes que asumen conforme a la desformalización los faculta para flexibilizar autónomamente las formas rituales, sin embargo, también creen que si no mediase este instituto, igual pudiesen tener las mismas facultades en virtud del principio de actuación de oficio, al que agregan otras directrices del derecho de fondo.

Dentro de los que estiman que la desformalización no es un principio, se manifiestan dos posturas. (I) La mayoría sostiene que existe la posibilidad de flexibilizar las formas rituales, en virtud exclusiva de principios sustantivos, (II) mientras que la minoría estima que la desformalización no es un principio y que el juez debe sujetarse exclusivamente a los márgenes que la ley establece, por lo no le es posible innovar, cambiar o crear formas procesales.

2. Si bien es imposible que se exija a los jueces resolver de maneras similares o poseer igual criterio sobre los alcances jurídicos de las normas, hay ciertos márgenes que resultan sobrepasados por una dispersión excesiva, como la que se ha manifestado en este estudio. La preclusión, por ejemplo, no puede ser pasada por alto en un procedimiento, pues sus alcances son de rango constitucional y garantizan el derecho que posee todo ser humano a ser juzgado en un plazo razonable.

3. Los diversas interpretaciones que se han visto en el desarrollo de los resultados que se dieron a conocer, no solo hablan de una confusión que se mantiene en el fuero interno de la judicatura sobre los alcances 
teórico prácticos del instituto en comento, sino que se exterioriza a una tramitación contradictoria que afecta a los justiciables. Esto plantea cuestiones de lege lata, en tanto la seguridad jurídica e igualdad ante la ley quedan mermadas, y de lege ferenda, porque en base a la problemática develada a través de esta investigación, queda abierta la posibilidad de efectuar correcciones por vía legislativa, a fin de precisar la poca claridad que existe en cuanto a este tópico, por parte de la judicatura.

4. Los legisladores fueron prudentes en estimar desde su génesis hasta su instauración que la desformalización no permite al juez omitir, crear, modificar o flexibilizar formas a su voluntad. La apertura a la capacidad de legislar por parte de los jueces es una de las consecuencias prácticas que se trató de evitar y que hoy se manifiesta debido, por una parte, a la redacción deficiente de la norma que la contiene y, por la otra, a la excesiva discrecionalidad que los jueces de familia de la muestra manifiestan en su accionar.

5. La desformalización es una característica intrínseca al rito establecido en la LTF que está preanunciada en el artículo $9^{\circ}$ de la misma. Ello implica que las formas establecidas en el procedimiento que propende a tutelar los derechos de la familia y la infancia, atendidos los bienes que protege, son por sí mismas suficientemente flexibles para otorgarle eficiencia y rapidez a su tramitación. No es una directriz jurídica, tanto por la exégesis del contexto normativo donde el instituto se encuentra inserto, las inconveniencias prácticas de estimarlo como tal y su historia legislativa.

\section{BIBLIOGRAFÍA}

Alpa, G. (2006) I principi generali (Segunda ed.). Milano: Giuffrè Editore.

Barak, A. (1995) La discrezionalità del giudice. (I. Mattei, Trans.) Giuffrè Editore.

Bone, R. (2003) Civil procedure, The economics of civil procedure. New York, E.E.U.U.: Fundation Press.

Carretta Muñoz, F. (2014) "La desformalización del proceso judicial de familia e infancia". Revista de Derecho de la Pontificia Universidad Católica de Valparaíso, Vol. XLII, 481-495.

Chiovenda, G. (1960) Istituzioni di diritto processuale civile (Vol. I). Napoli: Eugenio Jovene Editore.

De Santis, F. (2005) "Riforme processuale e "'disponibilitá" del regime preclusivo". Rivista Studi di Diritto Civile in Onore di Giuseppe Tarzia. Milano, Italia: Giuffrè. 
Dworkin, Ronald (2013) Talking Rights Seriously. London: Bloombsbury, p. 46.

Esser, J. (1961) Principio y norma en la elaboración jurisprudencial del derecho privado. Barcelona: Bosch, 498 pp.

Guastini, R. (2013) Distinguendo ancora. Madrid: Marcial Pons.

Losano, Mario (2002) Sistema e struttura nel diritto, Dalle origini alla Scuola storica. Milano: Giuffrè, p. 197.

Luiso, F. (2007) Diritto processuale civile. Milano, Italia: Giuffrè.

Luzzati, Claudio (2012) Principi e principi. La genericità nel diritto. Torino: Giappichelli, pp. 4-5.

MacCormick, Neil (2007) Intitutions of law. Oxford: Oxford University Press, pp. 28-30.

Monteleone, G. (2008) Preclusioni e Giusto processo: due concetti incompatibili. En G. Bongiorno (Ed.) Studi in onore di Carmine Punzi (págs. 413-422). Giappichelli.

Posner, R. (2008) How judges think. Cambridge: Harvard University Press, pp. 1-15

Redenti, E. (1957) Diritto processuale civile (Vol. I). Milano, Italia: Giuffrè.

Ross, A. (1959 ) On law and justice. New Yersey Clark.

SAssani, B. (1988) Impugnativa dell' atto e disciplina del rapporto. Padova, Italia: Cedam.

Schauer, Frederick (1991) Playing by the rules. Oxford: Clarendon Law Series, pp. 19-24.

Turner Saelzer, Susan (2002) "Los tribunales de familia”. Revista Ius et Praxis, Vol. 2, No 8, pp. 413-443.

Tesoriere, G. (1983) Contributo allo studio delle preclusioi nel proceso civile. Padova, Italia: Cedam, pp. 25 -51.

\section{JURISPRUDENCIA CITADA}

Corte de Apelaciones de San Miguel, dictada el 23 de marzo de 2016, en causa rol 879-2015.

Corte de Apelaciones de Valparaíso, sentencia rol 375-2008, (Repertorio, 2010, p. 662).

Corte de Apelaciones de Santiago, sentencia rol 4331-1998, dictada el 17 de marzo de 1999 (ID LegalPublishing 20677).

Corte de Apelaciones de Puerto Montt, sentencia dictada el 30 de agosto de 2010 (ID LegalPublishing 47003).

Corte de Apelaciones de San Miguel, sentencia rol 415-2010, dictada el 4 de octubre de 2010 (ID Westlaw Chile CL/JUR/8075/2010).

Corte de Apelaciones de San Miguel, sentencia rol 218-2010, dictada el 10 de octubre de 2010 (ID Westlaw Chile CL/JUR/2564/2010). 
Corte de Apelaciones de Concepción, sentencia rol 433-2009, dictada el 22 de abril de 2010 (ID Westlaw Chile, CL/JUR/2746/2010).

Corte de Apelaciones de Concepción, sentencia rol 2239-2008, dictada el 28 de agosto de 2009 (ID Westlaw Chile, CL/JUR/667/2009).

Corte de Apelaciones de Valparaíso, sentencia rol 375-2008, dictada el 09 de octubre de 2008 (ID Westlaw Chile, CL/JUR/3744/2008.

Corte de Apelaciones de Punta Arenas, sentencia rol 79-2007, dictada el 10 de diciembre de 2007 (ID Westlaw Chile, CL/JUR/251/2007).

Corte de Apelaciones de Santiago, sentencia rol 2916-2007, dictada el 30 de octubre de 2007 (ID Westlaw Chile CL/JUR/121/2007).

Corte de Apelaciones de San Miguel, Ayala con Trejo, 10 de mayo de 2010 (alimentos), Rol No 218-2010, ID LegalPublishing: CL/ JUR/2564/2010.

\section{NORMAS NACIONALES CITADAS}

Constitución Política de la República.

Convención Americana sobre Derechos Humanos.

Código Civil.

Código de Procedimiento Civil Chileno.

Código de Procedimiento Civil Italiano.

Código Orgánico de Tribunales.

Ley $\mathrm{N}^{\circ}$ 14.908, del 5 de octubre de 1962, Sobre Abandono de Familia y Pago de Pensiones Alimenticias.

Ley $\mathrm{N}^{\circ}$ 19.968, del 30 de agosto de 2004, Crea los Tribunales de Familia. Acta $N^{\circ}$ 262-2007, del 14 de diciembre de 2007, Auto Acordado sobre Principios de Ética Judicial y Comisión de Ética.

Acta N 98-2009, del 20 de mayo de 2009, Auto Acordado sobre Gestión y Administración de los Tribunales de Familia.

Código Iberoamericano de Ética Judicial.

Ley 19.980, del 20 de agosto de 2008, Establece bases de los procedimientos administrativos que rigen los actos de los órganos de la Administración del Estado.

\section{OTRAS REFERENCIAS}

Ministerio de Justicia de Chile (2012) Anuario estadístico sobre la Justicia de Familia. 


\section{ANEXO: ANÁLISIS PRIMARIO DE LA INFORMACIÓN RECOGIDA EN LAS ENTREVISTAS SEMIESTRUCTURADAS}

En este apartado se analizará el resultado de la información recogida en las distintas unidades de análisis donde se aplicaron las correspondientes entrevistas semiestructuradas. Tales entrevistas versaron esencialmente sobre los ejes temáticos que estructuran la idea de la desformalización en el contexto jurídico tratado en esta investigación, y de como este conocimiento "de sentido común" respecto del concepto analizado logra orientar en la práctica el actuar de los jueces de distintos tribunales del país en distintas situaciones vinculadas con la justicia de Familia.

Para poder ordenar y procesar de mejor manera la información levantada en terreno, se optó por un análisis de contenido cualitativo, el que -tal como se señaló anteriormente- se presenta como óptimo en su aplicación respecto del tipo de información recopilada, así como respecto de los objetivos de este estudio.

"El estudio base contiene el análisis de las entrevistas realizadas a 27 jueces de familia de diversas regiones del país. Las entrevistas han sido tomadas personalmente por el Investigador responsable. La elaboración de las preguntas y el lineamiento de los parámetros de valoración fueron hechas por el suscrito y el antropólogo social Marcelo Barría Bahamondes. Este último a su vez ha procedido al análisis de texturas dentro de la perspectiva de su profesión, bajo la dirección del investigador a cargo quien luego procedió al examen y valoración jurídica de los lineamientos atingentes a las hipótesis por las que se articulan los resultados aquí presentados. Los instrumentos de análisis y la prospección cuentan con la aprobación y certificación ética para el trabajo con humanos del comité de bioética de la Pontificia Universidad Católica de Valparaíso. Toda la información e insumos suministrados por las encuestas anónimas se encuentra bajo custodia del investigador responsable" 59 .

En cuanto a la muestra, las unidades de análisis seleccionadas fueron las siguientes, con el respectivo número de entrevistados en cada una de ellas. En total se realizaron 27 entrevistas en tribunales de familia a lo largo de todo Chile:

Cuadro \#1: Matriz de muestra - Unidades de análisis 


\begin{tabular}{|c|c|c|c|c|c|}
\hline $\begin{array}{l}\text { Juzgado } \\
\text { de familia } \\
\text { elegido } \\
\text { (lugar y } \\
\text { cantidad) }\end{array}$ & $\begin{array}{l}\text { Jurisdicción } \\
\text { (provincia y } \\
\text { comunas que } \\
\text { abarca) }\end{array}$ & $\begin{array}{l}\text { Número aprox. } \\
\text { de habitantes } \\
\text { en jurisdicción } \\
\text { respectivamente } \\
\text { al } 2002\end{array}$ & $\begin{array}{l}\text { Región } \\
\text { donde se } \\
\text { sitúa }\end{array}$ & $\begin{array}{l}\text { Número } \\
\text { total de } \\
\text { jueces del } \\
\text { tribunal }\end{array}$ & $\begin{array}{l}\text { Número } \\
\text { de jueces } \\
\text { entrevistados }\end{array}$ \\
\hline \multirow{2}{*}{ Arica (1) } & $\begin{array}{l}\text { Arica: } \\
\text { Arica } \\
\text { Camarones } \\
\end{array}$ & \begin{tabular}{|l|l}
185.268 \\
1.220 \\
\end{tabular} & \multirow{2}{*}{ XV } & \multirow[t]{2}{*}{8} & \multirow[t]{2}{*}{7} \\
\hline & $\begin{array}{l}\text { Parinacota: } \\
\text { General Lagos } \\
\text { Putre } \\
\end{array}$ & $\begin{array}{l}1.179 \\
1.977 \\
\end{array}$ & & & \\
\hline $\begin{array}{l}\text { Viña del Mar } \\
\text { (1) }\end{array}$ & $\begin{array}{l}\text { Valparaíso: } \\
\text { Viña del Mar } \\
\text { Concón }\end{array}$ & $\begin{array}{l}286.931 \\
32.273 \\
\end{array}$ & V & 8 & 3 \\
\hline Santiago (4) & $\begin{array}{l}\text { Santiago: } \\
\text { Cerrillos } \\
\text { Conchalí } \\
\text { Estación Cen- } \\
\text { tral } \\
\text { Huechuraba } \\
\text { Independencia } \\
\text { La Florida } \\
\text { La Reina } \\
\text { Las Condes } \\
\text { Lo Barnechea } \\
\text { Macul } \\
\text { Maipú } \\
\text { Nuñoa } \\
\text { Peñalolén } \\
\text { Providencia } \\
\text { Quilicura } \\
\text { Recoleta } \\
\text { Renca } \\
\text { Santiago } \\
\text { Vitacura }\end{array}$ & \begin{tabular}{|l}
71.906 \\
133.256 \\
130.394 \\
74.070 \\
65.479 \\
365.674 \\
96.762 \\
249.893 \\
74.749 \\
112.535 \\
468.390 \\
163.511 \\
216.060 \\
120.874 \\
126.518 \\
148.220 \\
133.518 \\
200.792 \\
81.499
\end{tabular} & XIII & $\begin{array}{l}52(13 \text { en } \\
\mathrm{c} / \mathrm{u})\end{array}$ & 9 \\
\hline Valdivia (1) & $\begin{array}{l}\text { Valdivia: } \\
\text { Valdivia } \\
\text { Corral }\end{array}$ & $\begin{array}{l}140.559 \\
5.463\end{array}$ & XIV & 6 & 4 \\
\hline
\end{tabular}




\begin{tabular}{|c|c|c|c|c|c|}
\hline $\begin{array}{l}\text { Punta Arenas } \\
\text { (1) }\end{array}$ & $\begin{array}{l}\text { Magallanes: } \\
\text { Laguna Blanca } \\
\text { Punta Arenas } \\
\text { Río Verde } \\
\text { San Gregorio } \\
\text { Antártica Chi- } \\
\text { lena: } \\
\text { Antártica } \\
\text { Cabo de Hor- } \\
\text { nos }\end{array}$ & $\begin{array}{l}663 \\
119.496 \\
358 \\
1.158 \\
\\
130 \\
2.262\end{array}$ & XII & 4 & 4 \\
\hline
\end{tabular}

Con la finalidad de abordar de mejor manera la gran cantidad de información registrada en función del objetivo principal de este estudio, se ordenaron los datos de las entrevistas en dos grandes dimensiones, cada una albergando dentro de sí otras subdimensiones y categorías o variables que resultaba pertinente investigar.

Las dos grandes dimensiones o ejes y sus respectivas categorías o temáticas específicas que orientaron las entrevistas son los siguientes:

1) Desformalización EN EL MARCo DE LA ESTRUCTURA DEL PROCESO: AUDIENCIA PREPARATORIA Y POSIBILIDAD DE SENTENCIA DEFINITIVA

- Posibilidad de dictar sentencia definitiva.

- Aplicabilidad del artículo 313 del CPC en función del artículo 27 de la ley 19968.

2) LA DESFORMALIZACIÓN: REPRESENTACIONES SOCIALES EN TORNO AL CONCEPTO: TEORÍA Y PRÁCTICA SOCIAL AL RESPECTO

- Comprensión del concepto a partir del sentido común.

- La desformalización y su lugar en el proceso judicial.

- Aplicaciones prácticas de la desformalización.

- La desformalización y su relación con las medidas de equidad.

- Desformalización y capacidad heurística del juez a partir del artículo 27 de la Ley de Tribunales de Familia. 
1) DESFORMALIZACIÓN EN EL MARCO DE LA ESTRUCTURA DEL PROCESO: AUDIENCIA PREPARATORIA Y POSIBILIDAD DE SENTENCIA DEFINITIVA

\section{(1.1.) Posibilidad DE Dictación DE SENTENCia EN AUdiencia PREPARATORIA. PUGNA DE CRITERIOS EN LA PRÁCTICA JURÍdICA EN EL CASO DE JUICIO DE ALIMENTOS}

El primer aspecto analizado en las entrevistas apuntó a desvelar la percepción de los jueces respecto de la posibilidad de dictar sentencia definitiva en la audiencia preparatoria, precisamente en consideración a los múltiples e hipotéticos escenarios que se podrían dar a partir de una interpretación más amplia de la desformalización.

Prácticamente la totalidad de los jueces entrevistados (26 jueces versus 1 juez que niega derechamente la posibilidad) contestaron que sí es posible dictar sentencia definitiva en esa instancia, mencionando explícitamente el "principio de oficialidad" del artículo 13 -que autoriza a tomar tal decisión cuando hay antecedentes suficientes y un derecho que está claro y no discutido- junto a lo dispuesto por los artículos 61 y 68; sin embargo los jueces también condicionaron tomar tal medida a una serie de variables o factores de contexto que permiten validar o justificar de mejor manera tal decisión, como por ejemplo en el caso de los juicios de alimentos, donde los jueces consideran difícil dictar sentencia inmediatamente debido a que por lo general se carece de todos los antecedentes para tomar una decisión. De esta forma, es la disponibilidad de la prueba el elemento que permite o no al juez tomar una determinación de carácter definitivo, incluso en la instancia preparatoria del proceso:

"Si (es posible) en los casos que se ha incorporado toda la prueba, las partes han hecho las observaciones a la misma y tú con las pruebas en ese momento cuentas con todos los antecedentes para resolver"

Juez \#14

"En juicios de alimentos generalmente no lo hago, porque no cuento con todos los documentos, todos los antecedentes en ese momento, salvo que las partes lleguen a un acuerdo obviamente y lleguen a una conciliación”

Juez \#1

"Cuando ambas partes están de acuerdo de pasar a juicio inmediatamente, se cuenta con la prueba, se dicta sentencia a continuación, se recibe la prueba y se determina la causa"

Juez \#10

Entre las situaciones que permiten actuar de esta manera, se mencionan dos casos donde los jueces observan que es posible dictar -con respaldo legal explícito- sentencia definitiva en etapa de audiencia preparatoria: 
en el caso de acuerdo entre las partes, o en el caso de solicitud de uno de los padres para salir del país mientras exista acuerdo entre los progenitores.

Adicionalmente, se mencionan otros casos que también permitirían actuar de la misma manera, como son aquellas situaciones de violencia intrafamiliar, en especial cuando el demandante no sabe bien cuál es su pretensión, así como casos de protección de menores, o en situaciones de divorcio de mutuo acuerdo cuando no existe ninguna controversia al respecto, entre otros.

Cuadro \#2 - Dictación de sentencia definitiva en audiencia preparatoria

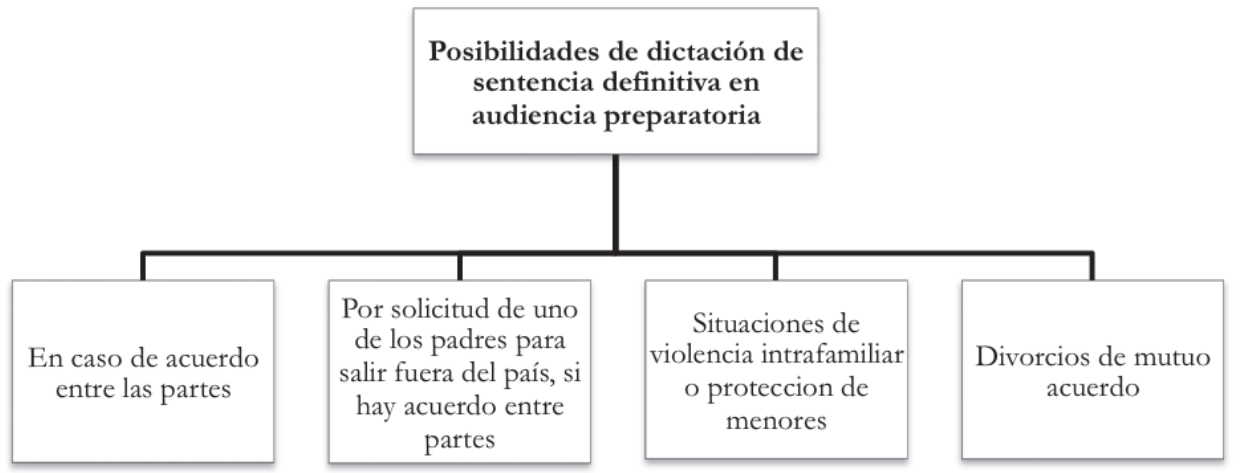

Fuente: Diseño propio

\section{(1.2.) DISENSO EN TORNO A LA POSIBILIDAD DE LA DICTACIÓN DE SENTENCIA ANTE UN DEMANDADO EN REBELDÍA. DISCUSIÓN EN TORNO AL SIGNIFICADO PROCESAL DE LA REBELDÍA EN UN CASO DE ALIMENTOS}

Respecto de la posibilidad de dictar sentencia en el caso específico de un demandando por alimentos en rebeldía, que está notificado y debe menos del mínimo legal, no existe un consenso entre los jueces respecto de la legalidad de la medida. Si bien en la mayoría de los casos los entrevistados no han estado ante aquella situación, estos creen que no es posible realizar tal acción en función del cumplimiento de normas de debido proceso, ya que la ausencia del demandado no implicaría -en su opiniónla entrega del consentimiento, elemento necesario para que se pueda dictar sentencia definitiva. Además, nuevamente el tema de la prueba aparece en mayor o menor grado para determinar la decisión del juez, al menos en los casos en que sí se cree que es posible dictar sentencia:

"No, yo prefiero no hacerlo por un tema de debido proceso, nada más" 
Juez \#3

"Bueno (para dictar sentencia definitiva), la ley dice que tiene que ser de común acuerdo para el juicio, pero yo lo he hecho... (uno de los fundamentos) es la desformalización"

Juez \#7

"Si, lo hago, en alimentos que no tengan demasiada cantidad de prueba si es que es contradictorio, porque en los alimentos sin contradictor las dicto todas en audiencia. Pero si es una causa de alimentos en que la prueba fue menor, teniendo contradictor, puedo dictar sentencia en la audiencia"

Juez \# 8

"(Dictar sentencia) se ha hecho, pero en lo personal no comparto la opinión"

Juez \#15

"Si no concurre, y por lo tanto no ofrece prueba y la parte demandante está de acuerdo, entiendo que no se justifica una segunda audiencia, porque no presentó pruebas"

Juez \#27

Aquí encontramos un conflicto en cuanto existen criterios dispares respecto de la posibilidad de dictar sentencia, y por lo mismo, ausencia de consenso al respecto. Ambos criterios son conocidos por los jueces, y finalmente es una elección personal la de adherir a uno u otro en la práctica jurídica. Por un lado existe el criterio que afirma que la rebeldía no implica necesariamente oposición o contradicción a la demanda -basándose en la exigencia de común acuerdo del artículo 61- por lo que por normas de debido proceso no se podría dictar sentencia definitiva, dejando esa decisión para una instancia posterior; en el otro lado, se menciona la existencia de un cambio doctrinal que sí entiende la rebeldía como una oposición a la demanda, por lo que existiría la posibilidad de dictar sentencia definitiva en ausencia del demandando:

"...el 61 habla de común acuerdo (para dictar sentencia definitiva), pero en ciertas oportunidades yo también lo he utilizado pese a que tengo mis dudas por el texto expreso, pero han sido casos muy puntuales donde claramente no hay mayor controversia"

Juez \#20

"No (creo posible dictar sentencia) porque el demandado en audiencia de juicio puede ofrecer prueba nueva"

Juez \# 14

"Creo que hay opiniones para decir que si y que no, estoy pensando sobre todo en la rebeldia, porque la rebeldia implica la voluntad de no participar 
en la audiencia preparatoria, pero hay ciertos derechos posteriores a la audiencia preparatoria que si uno dicta la sentencia definitiva ahi podrian verse conculcados, como la posibilidad de ofrecer prueba nueva... en contrario a este argumento, lo que yo revisaría... es que efectivamente la rebeldía sea en base a un emplazamiento personal... y no me daria por satisfecho el hecho de que se haya constatado domicilio en el lugar del juicio"

Juez \#13

Lo anterior, es decir, esta pugna de criterios para justificar o no la dictación de sentencia definitiva en la audiencia preparatoria, se puede resumir mejor en el siguiente testimonio que abarca en una sola reflexión las contradicciones observables en la práctica jurídica y las justificaciones que se dan al respecto, incluyendo de paso implícitamente la influencia de la desformalización en la toma de decisiones:

"...por el debido proceso yo no lo hago (dictar sentencia), pero no estoy en contra, por la agilidad, por la celeridad del proceso, quizás por los principios que informan en Familia que tratan que las personas obtengan rápidamente una solución a sus conflictos... pero considero que es mejor que se haga una modificación de la norma sobre todo en alimentos, que permita esto... Si bien la Ley de Familia tiene principios, no hay que perder de vista los principios generales del ordenamiento civil. Siempre le digo a los colegas cuando discutimos que (el demandado) al no ir (a la audiencia) niega todo, y como niega todo se opone a todo, y por ende el otro tiene que probar, y por qué tiene que probar si la ley ha contemplado una audiencia de juicio. Entonces están las dos visiones, una es la que pienso jurídicamente que apunta a la bilateralidad de la audiencia y el debido proceso, y lo otro que propenden jueces más innovadores, sobre todo con esto de la comisión que empezó a flexibilizar los criterios jurídicos"

Juez \#4

\section{(1.3.) Sobre la APliCABilidad DEL ARTículo 313 Del CPC EN RELACIÓN AL ARTÍCULO 27 DE LA LEY 19968 EN EL MARCO DE LA POSIBILIDAD DE DICTAR SENTENCIA DEFINITIVA EN AUDIENCIA PREPARATORIA}

Dentro de la misma temática relativa a la posibilidad o imposibilidad de la dictación de sentencia en la audiencia preparatoria, se aplicó una pregunta específica a los entrevistados relativa a la pertinencia de la apli- 
cación del artículo 313 del Código de Procedimiento Civil ${ }^{60}$ en relación al artículo 27 de la ley 19968 de Tribunales de Familia ${ }^{61}$ en la situación ya mencionada.

En este ámbito tampoco existe consenso entre los jueces respecto de la pregunta realizada, si bien la gran mayoría de los jueces seńala que no es posible ni pertinente aplicar tal norma en la situación señalada a pesar de su carácter supletorio o subsidiario. Existe, según se observa, entre la minoría partidaria de la viabilidad o pertinencia de la aplicación del artículo 313, una coincidencia con aquellos jueces que opinan que sí es posible dictar sentencia definitiva en la audiencia preparatoria.

Existen por tanto dos posturas, aquella que no considera procedente la aplicación del artículo 313 del CPC (ya que exige que no haya contradicción) en cuanto el estar en rebeldía implicaría contradecir u oponerse a la demanda, y aquellos que -en menor cantidad- piensan que sí es posible aplicar esa norma en ausencia del demandado -es decir, en contradicción a la demanda- con la finalidad de resolver de manera más rápida el conflicto entre partes en consideración a la urgencia de los derechos exigidos, a pesar de aquellos cuestionamientos vistos anteriormente referentes a las garantías del debido proceso.

La ausencia de consenso mencionada anteriormente queda graficada en las siguientes afirmaciones de los entrevistados, los que expresan sus razones jurídicas en pro y contra de la situación:

"Yo creo que es aplicable a (tribunales de) Familia, siempre que haya una modificación legal, porque sin modificación legal para mi es aplicable el Libro Primero y hasta el articulo 254, y de ahi para allá no es aplicable"

Juez \#24

"(No corresponde porque) si somos súper estrictos, no calza del todo, pero creo que también uno puede hacer eventualmente una interpretación más laxa y decir que tanto el 61 como eventualmente este por el 27 nos permiten cuando no hay... o sea, sin perjuicio de entender que efectivamente el no contestar la demanda supone una negación de los he-

60 Art. 313 (303) del CPC: Si el demandado acepta llanamente las peticiones del demandante, o si en sus escritos no contradice en materia substancial y pertinente los hechos sobre que versa el juicio, el tribunal mandará citar a las partes para oír sentencia definitiva, una vez evacuado el traslado de la réplica.

Igual citación se dispondrá cuando las partes pidan que se falle el pleito sin más trámite.

61 Artículo 27 de la Ley 19968. Normas supletorias: En todo lo no regulado por esta ley, serán aplicables las disposiciones comunes a todo procedimiento establecidas en el Código de Procedimiento Civil, a menos que ellas resulten incompatibles con la naturaleza de los procedimientos que esta ley establece, particularmente en lo relativo a la exigencia de oralidad. En dicho caso, el juez dispondrá la forma en que se practicará la actuación. 
chos, no hay una controversia fundamental expuesta, por decirlo así, y en ese sentido entonces, contando con la prueba uno podría fallar"

Juez \#20

"Por analogía si lo podría aplicar, pero no por ley"

Juez \#17

En cuanto a las situaciones jurídicas donde podría o no aplicarse esta normativa en conflicto, se torna interesante la reflexión de uno de los jueces en cuanto precisamente son las circunstancias y su gravedad o urgencia lo que les permite justificar la pertinencia de la medida jurídica en cuestión, justamente tomando la idea de desformalización para legitimar tal decisión:

"...estamos hablando de ciertas circunstancias, porque evidentemente habrá que eventualmente ponderar si estamos hablando simplemente de una divorcio, o de un cuidado personal, o si hablamos de una violencia intrafamiliar, por lo tanto la materia... la materia no te va a marcar la forma, pero la materia te va a marcar la ponderación que le des a ciertas normas o principios procesales. $Y$ ahi es donde creo yo que entra el tema de la desformalización"

Juez \#13

\section{2) LA DESFORMALIZACIÓN. REPRESENTACIONES SOCIALES EN TORNO AL CONCEPTO: TEORÍA Y PRÁCTICA SOCIAL AL RESPECTO}

La configuración de una idea orientadora de la acción respecto de una determinada actividad o situación es lo que le da vida a la idea de representaciones sociales. En ese sentido, en la primera dimensión analizada ya pudimos adentrarnos un poco al espacio donde se cruza el discurso y la práctica social (específicamente judicial) sobre la idea de desformalización, más específicamente en lo relativo a determinadas circunstancias que potencialmente son observables en la audiencia preliminar y que en cierto modo cimentan otras prácticas judiciales ya sea por analogía o por el espíritu que le da sentido y eficiencia.

En este apartado se busca detallar y profundizar más en la idea o concepto de desformalización, tratando de comprender mejor cuáles son los presupuestos ideológicos detrás de la comprensión del concepto por parte de los magistrados, así como su utilización práctica en relación a aspectos como la preclusión, la asimetría de poder en una audiencia y finalmente las posibilidades heurísticas de aplicar el Derecho para resolver un conflicto judicial. 


\section{(2.1.) LA DESFORMALIZACIÓN: SUS ALCANCES, LÍMITES, RASGOS Y ESTRUCTURA A PARTIR DE LA PERCEPCIÓN DE LOS JUECES ENTREVISTADOS}

Durante la entrevista, se solicitó a los jueces que intentaran formular una definición de la idea de desformalización, pero evitando lo más posible cualquier tipo de referencias jurídicas, es decir, se pidió una definición "de sentido común", amplia y lo menos técnica posible, esto con la intención de lograr una comprensión mayor respecto de cómo opera tal concepto de manera amplia en la práctica jurídica.

Las respuestas de los jueces apuntaron mayormente hacia la idea de desformalización como una forma de libertad de acción durante el proceso que permitía al juez ponderar de manera más eficaz aquellos aspectos que le permitirían fallar con fluidez, en detrimento de los aspectos rituales, procedimentales o de forma que ralentizan e imposibilitan resultados inmediatos por la misma estructura procedimental a cumplir.

En este último sentido, la desformalización es entendida como una forma de "liberarse" de parte de las exigencias administrativas del proceso, con la finalidad de responder con mayor prontitud y agilidad a las demandas presentadas. Tales formalidades administrativas son entendidas como parte del ritual o ceremonia que le dan estructura al proceso judicial, pero que también le restan flexibilidad y adaptabilidad. Lo anterior se resume en el siguiente esquema:

Cuadro \#3 - Percepción de los alcances del concepto de desformalización

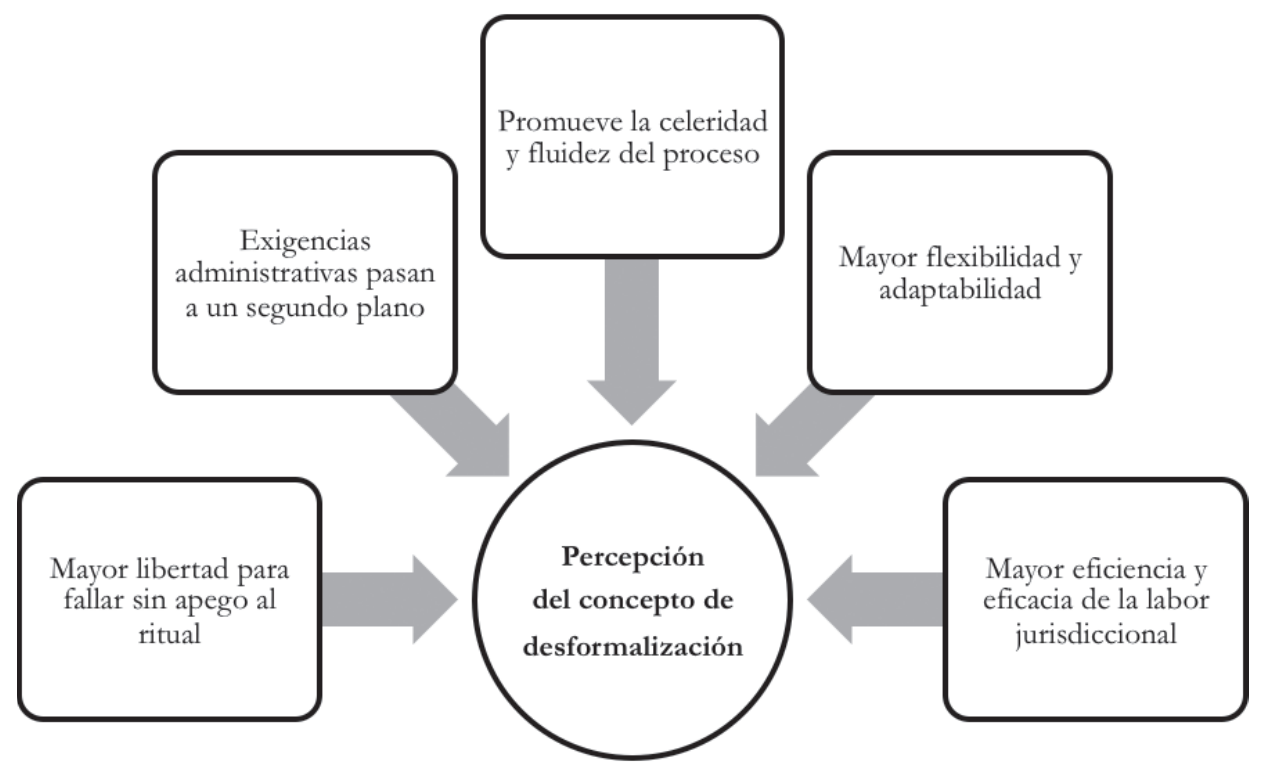

Fuente: Diseño propio 
La ausencia de formas y la negación de la rigidez procedimentales lo que caracteriza en primera instancia a la idea de desformalización. Adicionalmente, buena parte de los jueces entrevistados mencionan como parte de esta idea la de cercanía con los intervinientes en el proceso, una flexibilización o relajamiento de la distancia entre juez y partes involucradas que permite eventualmente un mayor entendimiento.

"(la desformalización) me alude a que tengo que centrarme más en el fondo de la discusión, tratar de resolver el fondo del conflicto juridico, en vez de prestarle mayor atención a incidencias de tipo procedimental o formales"

Juez \#2

"La desformalización implica desritualización, o sea, no hay rito, no hay ceremonia"

Juez \#4

“... desformalización es que no esté tan atado a las formas y que pueda ser un poco más ágil, que permita fluir de mejor forma los intereses de las partes en este caso..."

Juez \#15

"... desde el punto de vista del sentido común para mí tiene que ver con eso, que no hay un orden consecutivo expresamente establecido de como se hacen las cosas, hay que hacerlo un poco a la suerte de lo que se vaya dando en el sentido común de la audiencia”

Juez \#21

\section{(2.2.) FORMAS DE ENTENDER EL CONCEPTO DE DESFORMALIZACIÓN: PRINCIPIO JURÍDICO O CARACTERÍSTICA DEL PROCEDIMIENTO}

Dentro de la misma temática, se pidió a los entrevistados que intentaran realizar algún tipo de clasificación de la idea de desformalización, con la finalidad de poder asimilarla a alguna categoría menos abstracta y asequible. Las respuestas de los entrevistados pueden ser organizadas de la siguiente manera:

La desformalización es:

a) Un principio jurídico: 14 entrevistados - 51,8\%

b) Una característica del procedimiento: 12 entrevistados - 44,4\%

c) No sabe/no responde: 1 entrevistado - 3,7\%

De esta forma, la distribución de opiniones respecto de esta pregunta esencial puede expresarse a través del siguiente gráfico: 
Cuadro \#4 - Opiniones en torno a la idea de desformalización

\section{¿Qué es la desformalización?}

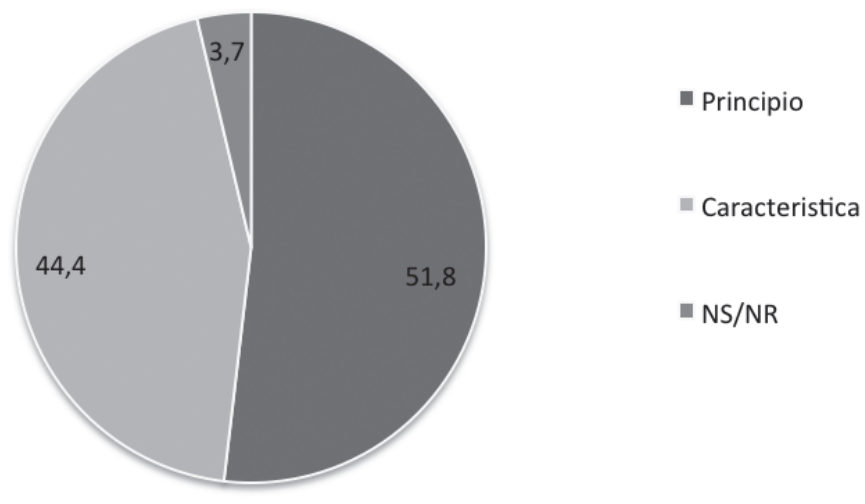

Fuente: Diseño propio

Como es posible apreciar, existen dos grandes ideas o enfoque entre los entrevistados respecto a qué es la desformalización, las que corren bastante parejas al menos en la muestra seleccionada para el estudio. Si bien este análisis es de carácter cualitativo, la finalidad de mencionar la distribución de las respuestas dadas busca tener una idea de la escasa ventaja que posee la idea de desformalización como "principio" $(51,8 \%)$ versus la idea de desformalización como "característica” (44,4\%), lo que hace pensar que sería temerario pensar que el primer enfoque se impone categóricamente sobre el segundo, situación que por lo demás no busca definir esta investigación.

En cuanto a las razones que se dan para justificar cada uno de los enfoques, es posible decir que desde el grupo aparentemente mayoritario que entiende la idea de desformalización como principio, encontramos las siguientes reflexiones y observaciones sobre los alcances de este concepto, basadas en una necesidad de darle mayor fluidez al proceso en función de las características esenciales de la justicia de Familia, específicamente en lo relativo a la celeridad en la obtención de una solución al conflicto presentado al juez, así como mayor autonomía para tomar decisiones:

"...es un principio, claramente, no es una regla, hay que llenarlo de contenido, y ahi varian los criterios... a veces siento que la desformalización puede llegar a pasar por poco lo que dice la norma, y eso yo creo que es preferible 
que, obviamente nosotros somos jueces y tenemos superiores, se propenda a las modificaciones legales para que en un Estado de Derecho todo se haga conforme a lo que indica el Estado de Derecho"

Juez \#4

"(la desformalización como principio) implica no seguir al pie de la letra muchas veces el procedimiento determinado en cuanto audiencia preparatoria... (implica) saltar algunos ritos, saltar algunas informaciones para efecto de ir llegando a explorar rápidamente una solución colaborativa entre las partes"

Juez \#9

"Yo creo que hay que entender que la desformalización es de la misma categoría de los demás, es decir, un principio del procedimiento de los Tribunales de Familia en general"

Juez \#13

"Lo entiendo como un principio jurídico que está muy asociado a la materia sobre la cual versa precisamente la justicia de Familia"

Juez \#19

Por otro lado, los argumentos esgrimidos por quienes defienden el enfoque de la desformalización como una característica del proceso, apuntan hacia su comprensión como un mero rasgo del procedimiento judicial de Familia, aplicado a partir de los objetivos esenciales que busca este; adicionalmente, la desformalización es entendida como una característica en cuanto se configura como aquella parte de la técnica o protocolo que permite espacios de flexibilidad y que está dentro del marco de posibilidades de maniobra que posee el juez dentro del proceso:

“...más que un principio, sería una característica, un rasgo del procedimiento de Familia que se aplica sobre la base de los principios más generales como son el interés superior del niño, la búsqueda de acuerdos, etc., pero sería de todas formas una característica"

Juez \#18

"Yo lo entiendo como una característica inherente a las normas, al procedimiento"

Juez \#22

"Si (la desformalización) es un principio, yo entiendo que sería algo de orden valórico, en cambio, esto no es valórico sino que te dice 'mire, es una forma en la cual usted tiene que actuar dentro de la audiencia, dentro del proceso', pero no es un principio. Un principio te ataca el término, o va englobado en el término valórico"

Juez \#26 
"No creo que sea un principio. Si bien está por ubicación legal dentro de eso, me parece más una facultad que te da la ley para ser menos rígido en ciertas materias en conformidad o en la forma como te lo señala, y dependiendo de la materia"

Juez \#8

\section{(2.3.) POSIBILIDAdeS DE USO DE LA DESFORMALIZACIÓN EN LA PRÁCTICA JUDICIAL}

Cuando se pregunta a los magistrados sobre cómo han ejercido de manera empírica la idea de desformalización, las respuestas de los entrevistados se han orientado básicamente hacia la búsqueda de la flexibilidad en las formas de la práctica judicial, expresada en situaciones como el uso de lenguaje más coloquial (no uso de palabras sacramentales), o la aplicación laxa de ciertas exigencias informativas, documentales o de testigos, mayor horizontalidad con las partes, recepción o exclusión de pruebas tardías (por lo general previa consulta a la contraparte) o salvaguardar omisiones de la audiencia preparatoria, llamados a conciliación, etc. todo enfocado principalmente a la búsqueda de un fallo inmediato o en su defecto, de mayor solidez jurídica.

“...yo flexibilizo algunos términos, dependiendo de las personas con las cuales uno está tratando, porque si estoy tratando con personas con abogados particulares no necesito flexiblizar el lenguaje. En eso, en la forma, no exijo a raja tabla o perentorio que un testigo, por ejemplo, pudiera venir un poquito menos formal vestido...¿Qué otra cosa? A veces por ejemplo me ha bastado con el carnet de conducir porque no tiene el carnet de identidad y nadie duda que es la persona, cosas asi. Pero principalmente (la desformalización se aplica en) poder volver atrás en algunos puntos.

Juez \#8

"...las partes han hecho las observaciones a la prueba, pero el tribunal no ha dado el veredicto y adviertes que hubo un vicio en la audiencia preparatoria, por ejemplo. Tú en virtud de la desformalización podrias citar a una audiencia a las partes para salvar esas omisiones o errores sin anular todo lo obrado en el procedimiento"

Juez \#14

Lo anterior se resume en el siguiente gráfico:

Cuadro \#5 - Formas de expresión práctica de la desformalización 


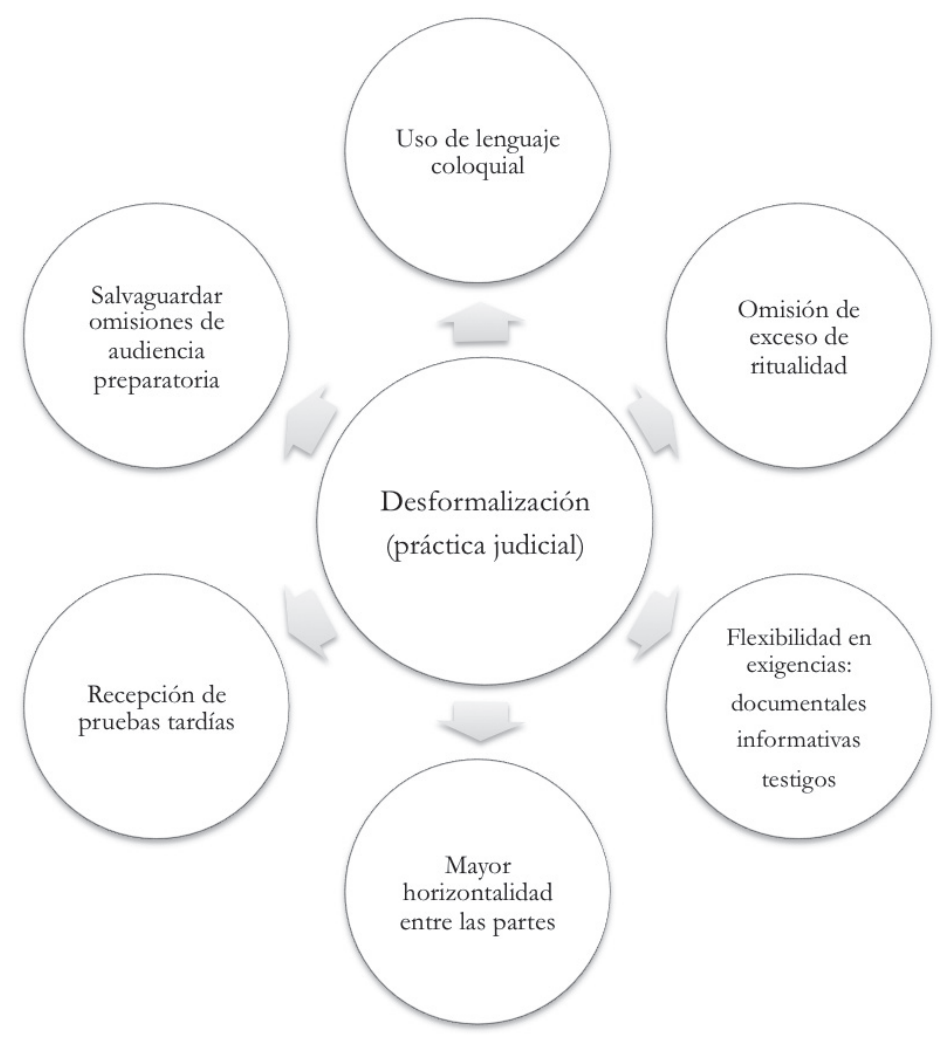

Fuente: Diseño propio

Es interesante observar como a veces las variables socioecónomicas del entorno del tribunal también influyen en la percepción y práctica que ejercen los jueces cotidianamente, al punto de llegar a reconocer que se busca dictar soluciones que si bien se alejan de la máxima pulcritud y apego al Derecho, logran conseguir que se cumplan ciertos objetivos de justicia natural que permiten alcanzar resultados óptimos. De esta forma, y para justificar esta decisión, se mencionan casos vinculados con medidas de protección, ya que en esos casos sería posible abordar temas que van más allá de lo que la norma jurídica estricta establece, ello con la finalidad de lograr sentencias de mayor efectividad.

"...la realidad de este tribunal es que la controversia generalmente es de muy bajo nivel económico, generalmente nuestros usuarios son de la Corporación... hay más espacio para la desformalización, y permite llegar a una solución que jurídicamente puede no ser la mejor, pero va a permitir darle a la persona que pretende caso... una pensión de alimentos, contar con el título para empezar a cobrar lo antes posible"

Juez \#18 


\section{(2.4.) LÍMITES Y EXCEPCIONES EN LA APLICACIÓN DE LA DESFORMALIZACIÓN}

La desformalización, de todas formas, tiene sus límites en la práctica judicial. Según la opinión mayoritaria de los entrevistados, no sería procedente -como regla general- que se permita al demandado contestar en la audiencia preparatoria, en cuanto en virtud de la desformalización no se podría pasar a llevar otras normas del derecho de Familia y especialmente las oportunidades procesales (plazos) que ofrece este para realizar determinadas acciones; sin embargo los entrevistados contemplan como excepción a esto ciertas situaciones específicas como son la petición para autorizar un viaje fuera del país, o en situaciones de violencia intrafamiliar, donde eventualmente se podría tomar la opinión del demandado como una suerte de contestación, además de dos casos más de tipo extraordinario: la recepción de pruebas que podrían ser relevantes para el caso siempre y cuando sean contundentes, así como casos excepcionales donde la notificación al demandado haya sufrido alguna situación que evitara su cumplimiento; sin embargo, como se mencionó anteriormente, formalmente no correspondería tal situación en cualquier otro caso posible según la regla general:

"No (lo permito) por ningún motivo, porque la ley establece claramente los plazos de contestación... la desformalización, esta flexibilidad no se da para beneficiar a ninguna de las partes, la flexibilidad se da para facilitar el proceso, el término de la causa, por lo tanto debe haber certeza jurídica para todas las partes y el proceso no puede quedar en manos de una de las partes... por lo tanto si tú lo permites, el proceso (podría quedar) en manos del demandado y el demandante queda ahi absolutamente en desventaja"

Juez \#14

"Yo no lo permito, salvo en los procedimientos que nosotros permitimos la comparecencia personal, por ejemplo, que tenemos acá violencia intrafamiliar, salida del pais, en que dejamos a las personas actuar solas y llegan a la audiencia preparatoria y ahi si eventualmente les tomo su opinión como una suerte de contestación"

Juez \#5

"Por la desformalización no (permito la contestación), solamente podria contestar en la audiencia preparatoria, a mi juicio, en el evento que por algún motivo se anulara la notificación o quedara sin efecto por algún motivo, y que esté dentro del plazo para contestar y tenemos la audiencia y por economía procesal le permitiría contestar"

Juez \#8 
A partir de lo anterior, y en base a la percepción de la mayoría de los entrevistados, se establece que la idea de la desformalización en la práctica no podría - o al menos no debería normalmente- pasar a llevar ciertas normas básicas del debido proceso -como son los plazos- en la justicia de Familia, aunque también se hace mención crítica de lo breves que son tales plazos para que las partes puedan conseguir ayuda legal, principalmente de la Corporación de Asistencia Judicial, lo que se traduce en un perjuicio para las partes, especialmente la demandada.

Por otro lado, existe una opinión minoritaria de magistrados que creen que el demandado sí podría contestar la demanda en la audiencia preparatoria, pero esto funcionaría a modo de situación especial; algunos entrevistados afirman que esta regla sería de carácter legal, sin mencionar la norma específica que lo faculta, pero de todas maneras hay consenso de que se trata de una instancia con posibilidades limitadas de desarrollo y bajo circunstancias muy precisas: 1) que la contraparte acceda a esto; 2) que las partes acudan con abogados particulares (o públicos), es decir, que hayan logrado superar la barrera mencionada en el párrafo anterior; 3) que estos abogados busquen generar controversia; en este caso la decisión del juez que permite en una primera instancia esta posibilidad de desformalización se retrae inmediatamente hacia un espacio más reducido y ajustado estrictamente a la ley, con la finalidad de evitar que tales conflictos deriven en situaciones de mayor complejidad.

"Yo creo que si se puede...con matices se permite la contestación ahi, pero el matiz que me ha tocado ver es que si vienen con abogados particulares o que controviertan, porque si se genera una controversia acerca de esa procedencia, ahi la decisión al menos que yo tomo se ajusta mucho más a la ley porque ese conflicto podría quedar escalada con apelaciones, casaciones, cosas asi”

Juez \#18

En el caso de existir importantes asimetrías económicas y culturales entre las partes, la desformalización se presenta para los entrevistados como una forma de darle una oportunidad al demandado (que está en desigualdad de condiciones) para que pueda enfrentar de mejor manera el proceso; en ese sentido, hay consenso general entre los jueces respecto a que debe tratarse de un caso extremo, ya que ellos también deben garantizar a la otra parte el cumplimiento del debido proceso, por lo que una de las salidas que permite la desformalización sería la suspensión de la audiencia para que el demandado pueda volver con el patrocinio de un abogado propio o de la Corporación de Asistencia Judicial. Se busca así 
equilibrar la situación y dar la chance para contestar de la mejor manera posible:

"(en un caso asi) podría suspender y designarle abogado... invocaría normas del debido proceso porque los jueces tienden poco a aplicar las normas constitucionales o las normas internacionales. Yo creo que uno puede aplicarlas perfectamente, no lo limitarse a la norma textual de la ley de Familia"

Juez \#27

"(en un caso asi) yo lo suspendo, pero solamente para designarle un abogado, si es que no tiene los medios para contratarlo, y para que presente la demanda de compensación económica y nada más"

Juez \#8

"En casos de compensación económica yo si permitiría contestar en la audiencia, porque es un caso especial. Ahora en otros casos no permitiría contestar, si veo a una persona que está deprivada socioculturalmente, o bien a mis ojos por la pura percepción, inmediación, presenta algún problema para expresarse, bueno, entonces en ese momento pensaria en suspender la audiencia y por el principio del derecho a la defensa, a la debida defensa, le designaría un abogado"

Juez \#22

\section{(2.5.) PRECLUSIÓN Y POSIBILIDADES DE APLICACIÓN DEL ARTÍCULO 27 DE LA LEY DE TRIBUNALES DE FAMILIA}

Otra importante situación observada en el discurso de los entrevistados vinculada con los límites de la desformalización -especialmente si pensamos en las tensiones y/o fracturas que podrían darse en función del cumplimiento del debido proceso- es la relativa a la preclusión.

A partir del análisis de lo expresado por los jueces, existe controversia respecto de este punto ya que para algunos entrevistados la preclusión sigue operando de todas formas firmemente, sin haber espacio para flexibilidad de ningún tipo en función de la idea de desformalización, en especial cuando la parte que solicita algo cuenta con patrocinio letrado. Sin embargo, para buena parte de los jueces entrevistados sí sería posible obviar u omitir la preclusión en función de la idea de desformalización (sin descartar otras normas o principios procesales que apoyan la decisión), es decir, con la finalidad de hacer menos complejo, más fluido y eficiente el proceso, en la medida que se trate de una situación que amerite tal decisión y que exista acuerdo entre las partes.

Ahora bien, más específicamente, es de opinión general de este grupo de magistrados que en caso de patrocinio letrado la preclusión debería operar, a menos que tal hecho sea muy perjudicial para la parte afectada 
por lo que sería posible distinguir al menos dos situaciones donde abstenerse de aplicarla: a) ante un caso serio de defensa técnica inadecuada, se podría declarar el abandono de derecho a la defensa y se suspende la audiencia; y b) en causas de protección donde una aplicación rígida de la preclusión derivaría en una situación que atente contra el interés superior del niño.

"Si, le doy valor a la preclusión. Es que vuelvo a repetir, es desformalizado (el proceso), pero no desordenado".

Juez \#9

"...en las causas contenciosas que vienen con abogado me parecería impresentable que el abogado me saliera con que se le quedó una prueba en el tintero... ahi tienes dos opciones... declarar el abandono del derecho a la defensa y suspender audiencia, porque en el fondo no está bien preparado, o la preclusión. Pero en las causas de protección no puede regir esa norma tan tajante, porque lo que nos interesa es el interés superior del niño"

Juez \#27

Para justificar un actuar flexible ante la preclusión, algunos jueces hablan de la pertinencia de esta medida a partir de la oralidad en que se basa la instancia judicial en cuestión (audiencia preparatoria y especialmente la de juicio que es cuando se suelen presentar pruebas tardíamente), por lo que mientras la audiencia no se haya acabado, la posibilidad de flexibilizar las formas siempre estaría presente -concretamente dando traslado de alguna prueba nueva- no obstante el punto crítico para poder dar luz a esta posibilidad radica en que la otra parte no se oponga a esto; en caso contrario, es decir, de existir oposición, implicaría una nueva ponderación de la situación, y la obligación de aceptar la preclusión.

"Es que creo que la preclusión en un procedimiento oral y desformalizado no es tan estricta, no es tan absoluta"

Juez \#15

"Yo en general trato de marcar los tiempos, pero también debo reconocer que si llega a suceder una situación como esa en que se le olvidó una prueba, le doy la opción a la contraria, le pregunto ‘Hay algún inconveniente?'. Si la contraria no tiene inconveniente la acepto. Si la contraria se opone, entiendo queda cerrada la posibilidad"

Juez \#20

"P: ¿Es posible en virtud de la desformalización omitir la preclusión de esas etapas (procesales)?

R: Yo lo he hecho, pero dando traslado. Si la otra parte no tiene ningún inconveniente, que generalmente no lo tienen, si lo acepto"

Juez \# 23 
En síntesis, es posible graficar de la siguiente forma la opinión de los entrevistados respecto de la preclusión y su relación con la idea de desformalización:

Cuadro \#6 - Opinión de los jueces en torno a la preclusión

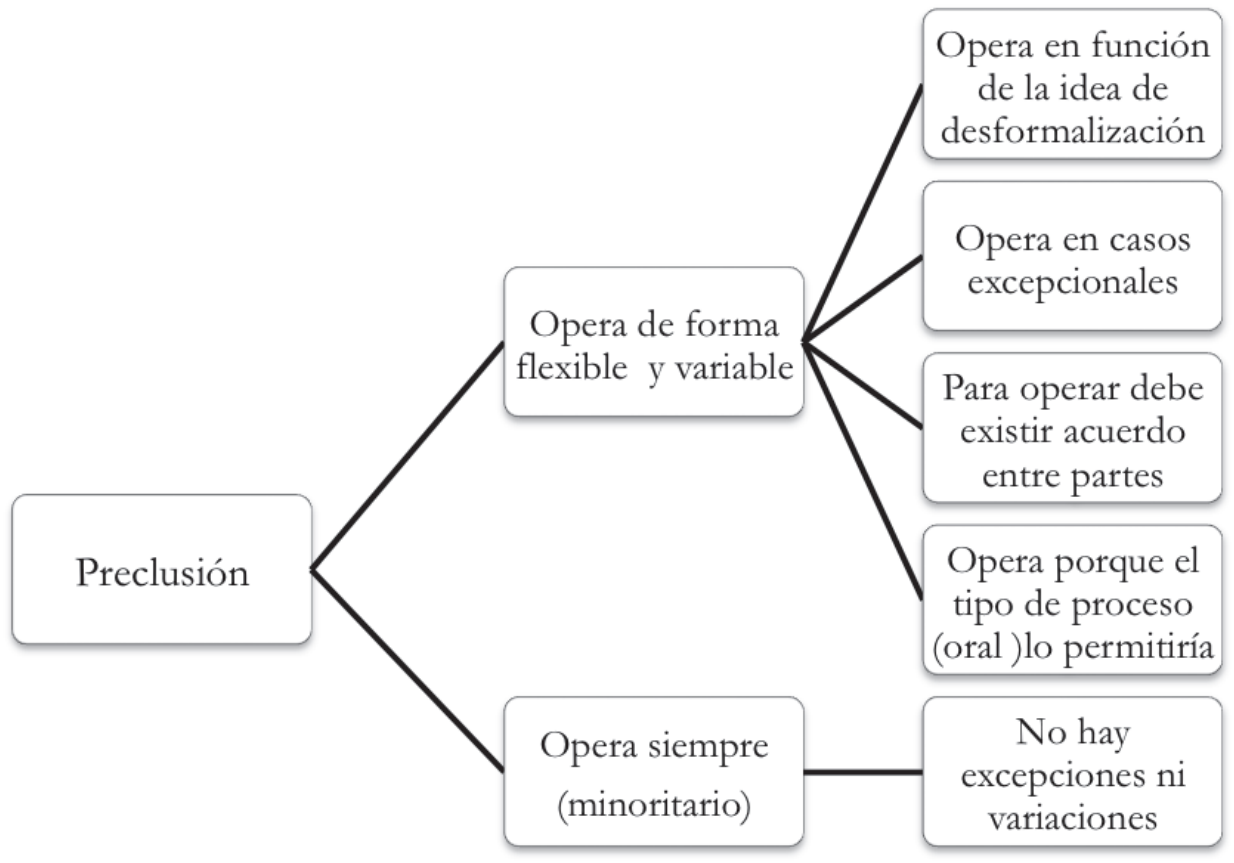

Fuente: Diseño propio

Finalmente, en esta parte de la entrevista se consultó a los magistrados sobre su experiencia en la aplicación de las instancias que contempla el artículo 27 de la Ley de Tribunales de Familia ${ }^{62}$. La gran mayoría de los entrevistados afirma no haber tenido nunca que encontrarse en esa situación, ni menos ha tenido que "crear un trámite" alguna vez, y que de darse tal hecho, tendría que pensar en como actuaría según el contexto. Por otro lado, una minoría de los entrevistados piensa que no correspondería que el juez tomara el rol de creador de Derecho -a pesar que tal artículo deja en manos del juez como dis-

62 Artículo 27 Ley 19.968 de Tribunales de Familia: Normas supletorias. En todo lo no regulado por esta ley, serán aplicables las disposiciones comunes a todo procedimiento establecidas en el Código de Procedimiento Civil, a menos que ellas resulten incompatibles con la naturaleza de los procedimientos que esta ley establece, particularmente en lo relativo a la exigencia de oralidad. En dicho caso, el juez dispondrá la forma en que se practicará la actuación. 
poner de la situación- ya que por un tema de certeza jurídica y transparencia debe apegarse lo más posible a la norma legal escrita.

Solo 3 (un 10\% aproximado) de los 27 magistrados afirman haber estado en esta instancia, no creando trámite, sino que básicamente aplicando normas del Código de Procedimiento Civil como las establecidas en el articulo 88 para los incidentes o el artículo 543 para algunos apercibimientos.

“... a mi me gusta la aplicación de la norma legal... la gente más moderna está más con la teoría de que los principios constituyen derechos, pero como me formé en el criterio de la escrituración, todo el procedimiento (debe ser) escriturado... la gente sabe por qué estoy fallando de esta manera; la publicidad, la transparencia son fundamentales"

Juez \#24

"A ver, asi como inventar no, porque he recurrido para lo que yo quiero lograr, a las medidas para mejor resolver, por ejemplo, que es el CPC en el fondo, pero lo hago oralmente, lo hago buscando un objetivo que, digamos, no tengo por dónde" Juez \#1. 